
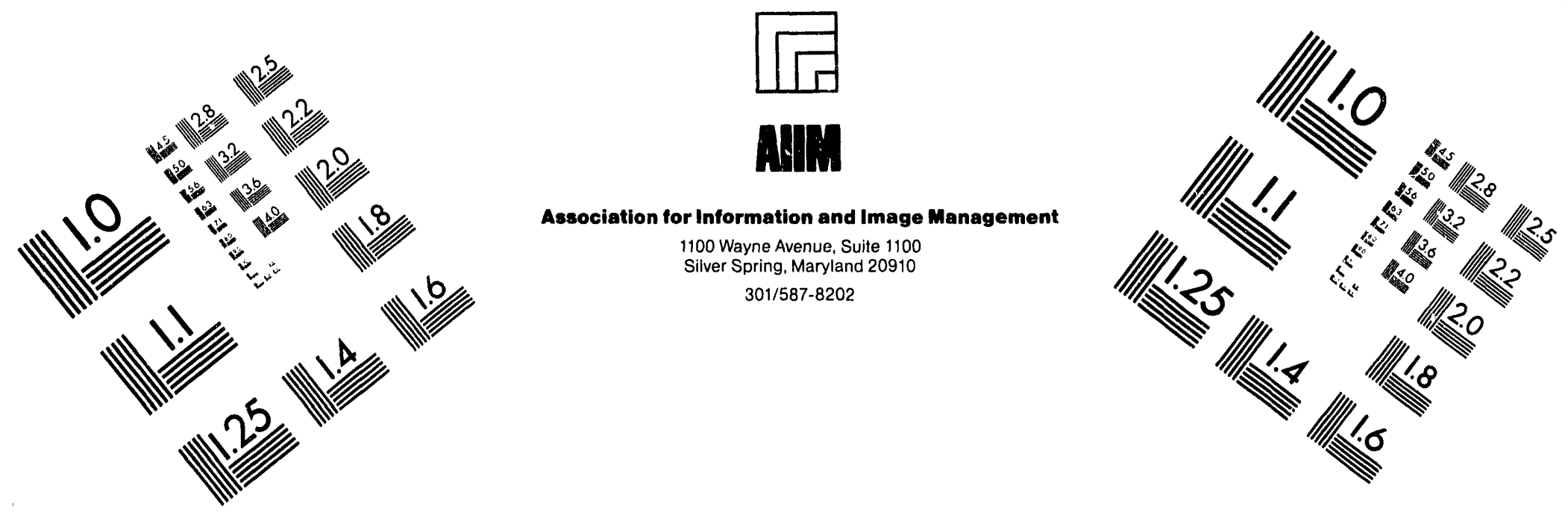

Centimeter

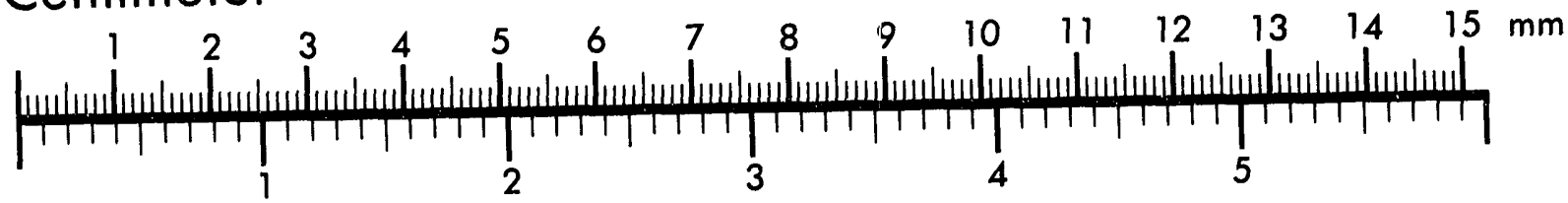
Inches
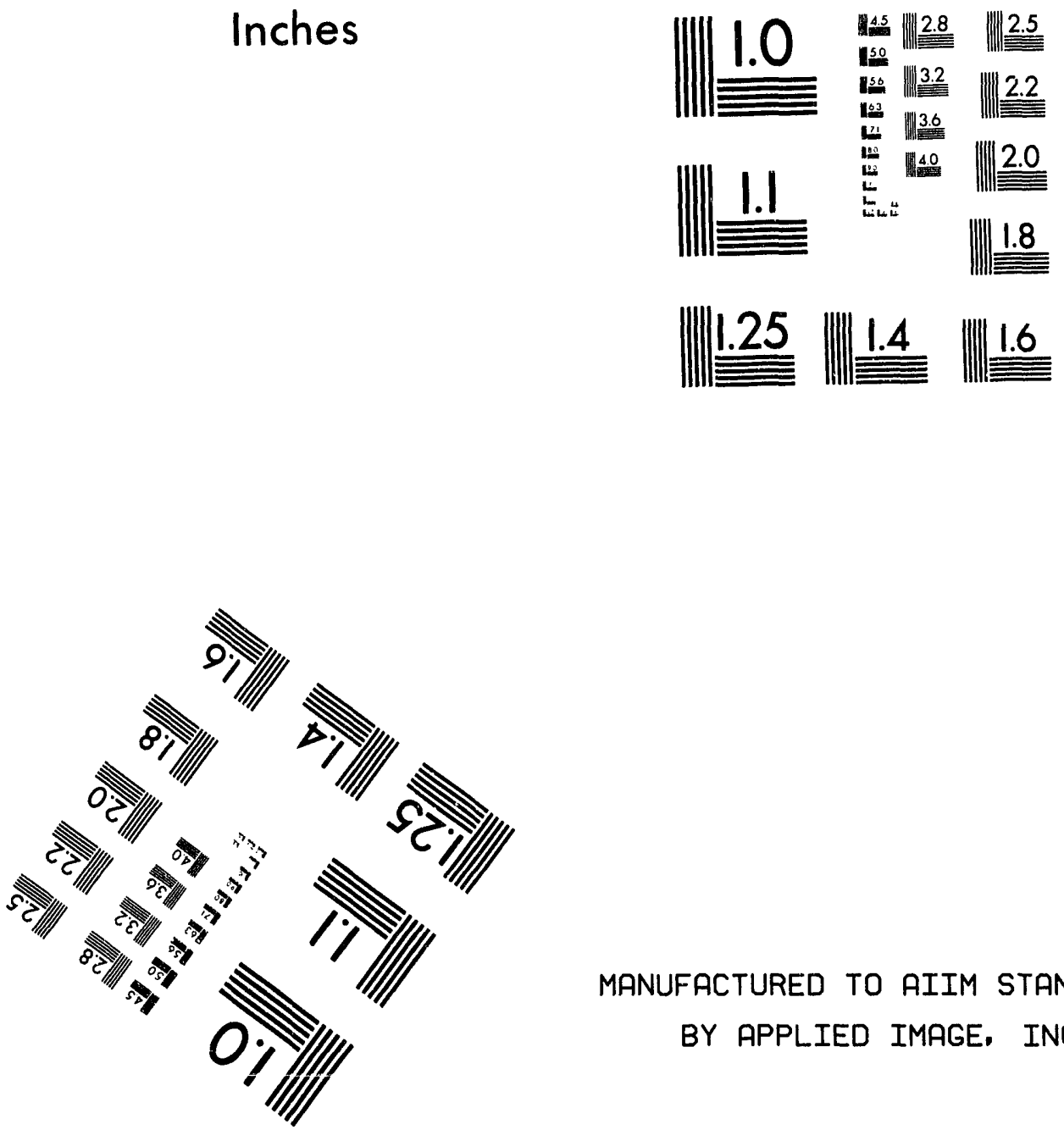

MANUFACTURED TO AIIM STANDARDS

BY APPLIED IMAGE, INC.

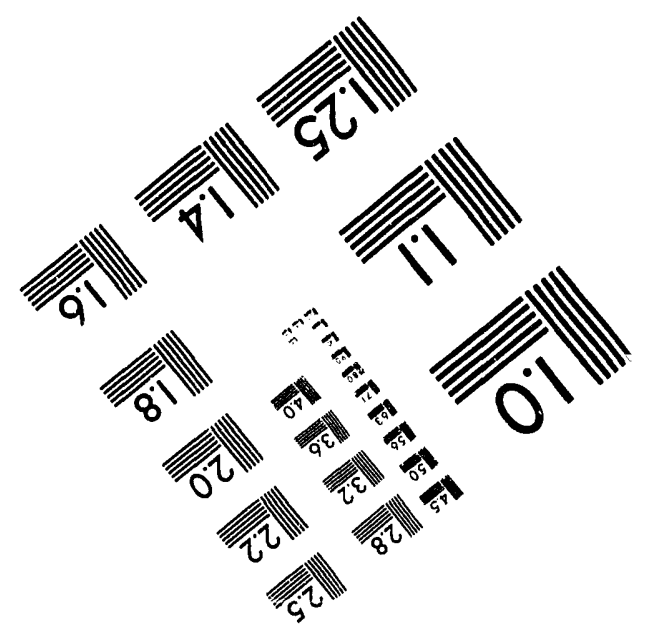



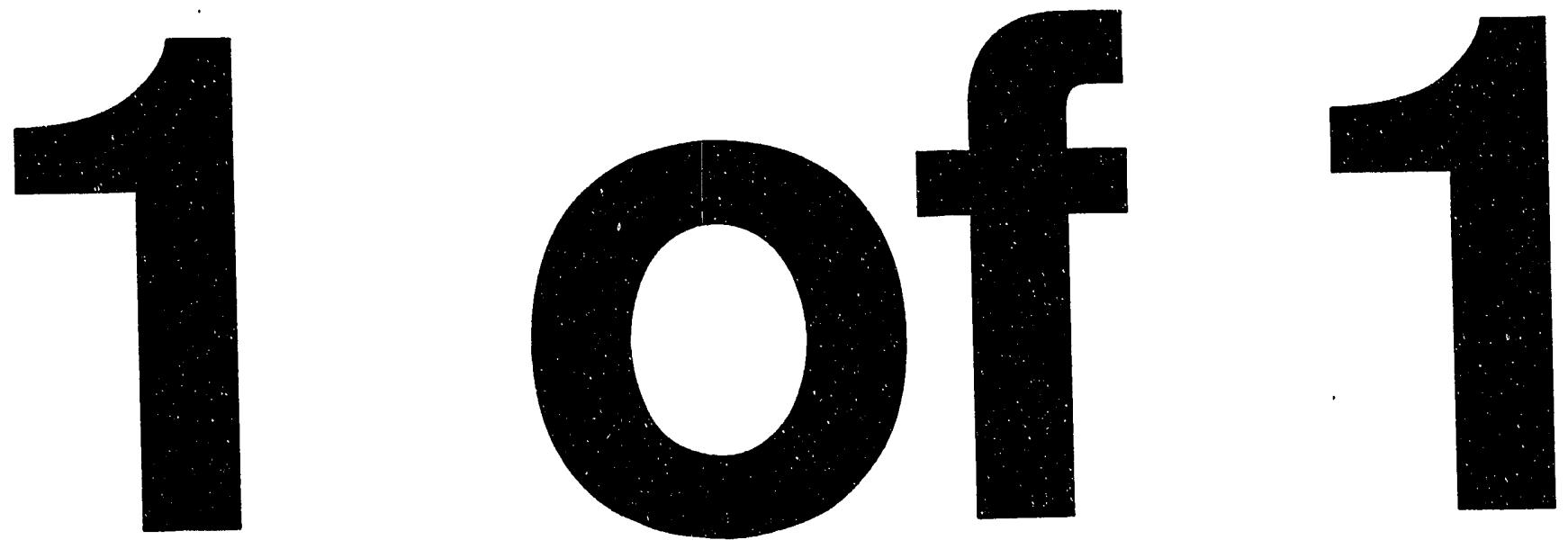


\section{Summary Report on Project SIREN (Search, Intercept, Retrieve, Expulsion, Nuclear)}

David Buden

Published December 1992

\section{Idaho National Engineering Laboratory EG\&G Idaho, Inc. Idaho Falls, Idaho 83415}

Prepared for the Strateglc Defense Initlative Organization

Program Number N0626 and for the

U.S. Department of Energy Offlce of Energy Research Under DOE Fleld Offlce, Idaho Contract DE-AC07-76ID01570 


\begin{abstract}
Project SIREN (Search, Intercept, Retrieve, Expulsion, Nuclear) has evaluated the technologies and operational strategies needed to rendezvous with and capture aerospace radioactive materials (e.g., a distressed or spent space reactor core) before such materials can reenter the terrestrial atmosphere and to move these captured materials to a space destination for proper disposal. The use of systems external to a satellite allows multiple attempts to prevent the nuclear materials from reentering the atmosphere. SIREN also has investigated means to prevent the breakup of nuclear-powered systems already in space. The SIREN project has determined that external means can be used reliably to prevent nuclear materials from reentering the terrestrial environment, prepared a computer model that can be used to evaluate the means to dispose of radioactive materials, assessed the hazards from existing nuclear power systems in space, and in discussions with Russian Federation representatives determined interest in joint activities in this area.
\end{abstract}




\section{SUMMARY}

Project SIREN (Search, Intercept, Retrieve, Expulsion, Nuclear) has evaluated the technologies and operational strategies needed to rendezvous with and capture aerospace radioactive materials (e.g., a distressed or spent space reactor core) before such materials can reenter the terrestrial atmosphere and to move these captured materials to a space destination for proper disposal. The use of systems external to a satellite allows multiple attempts to prevent the nuclear materials from reentering the atmosphere. SIREN also has investigated means to prevent the breakup of nuclear-powered systems already in space. Such systems currently number about 40, counting the USSR RORSAT satellites and U.S. SNAP-10A, Transit, and Nimbus satellites.

Major accomplishments of the program to date have included:

- Determination that external means can be used reliably to prevent nuclear materials from reentering the terrestrial environment. The technology base to implement a SIREN vehicle has been assessed. Basic technologies exist or are planned for all but the power system detachment mechanism. System level integration has not been done.

- Preparation of a computer model that can be used to evaluate different tracking, capture, and disposal options to perform SIREN missions. The computer model called THOR includes both a data base to describe all the elements needed in a SIREN mission and a mission analysis capability. The program is also applicable to nonnuclear servicing and maintenance activities and to space debris remediation analysis. No similar computer program is known to exist.

- $\quad$ Assessment of the degree of hazard from existing nuclear power systems in space. The results show that there is a significant risk of the formation of a belt of radioactive material at $900-1000 \mathrm{~km}$ altitude.

- Discussions with representatives of the Russian Federation that indicated interest in joint safety activities related to external disposal of space nuclear systems. The discussions were not further pursued because of the need for formal U.S. policy in this area. However, there is an effort to start a joint safety working group with external disposal means as an agenda item.

Many of the planned activities for SIREN were never completed. The SIREN project was terminated because funding was cut off. With the increased interest in nuclear energy for power and propulsion, there are a number of near-term activities that should be pursued. These include:

- $\quad$ Completion of the THOR data base to provide a rapid assessment tool for servicing and maintenance projects and for analysis of SIREN missions.

- $\quad$ Support for the proposed safety working group with the Russian Federation in the development of ideas to prevent reentry of radioactive sources into the Earth's environment from space.

- Development of guidelines for construction of space nuclear systems that facilitate disposal (such as, structural strengthening at the center of mass for attachment of booster rockets). In addition, recommendations should be prepared for modifications of space infrastructure for use in SIREN missions. Similar guidelines would apply to servicing, maintenance, and disposal of nonnuclear systems. 
Longer-term activities should include a space demonstration of (a) rendezvo' s $s$ with a nuclear-powered satellite, (b) radiation measurements and high-definition video pict, res of the satellite, and (c) attachment of a sensor package to the satellite for continued monitoring of its status and to simulate attachment of a booster for disposal. A radioisotope-powered Transit satellite in low Earth orbit is a good candidate for this mission. The estimated cost is $\$ 35-40$ million, based on use of a Pegasus aircraft launch vehicle to avoid inclination changes, a standard satellite bus, and existing space qualified sensors. 


\section{CONTENTS}

ABSTRACT $\ldots \ldots \ldots \ldots \ldots \ldots \ldots \ldots \ldots \ldots \ldots \ldots \ldots \ldots \ldots \ldots \ldots \ldots \ldots$, ii

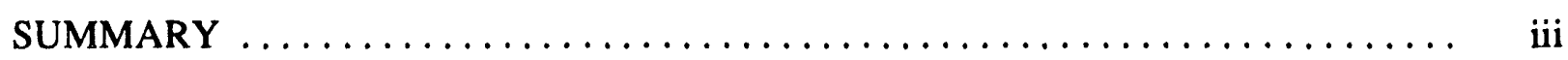

1. PURPOSE AND BACKGROUND $\ldots \ldots \ldots \ldots \ldots \ldots \ldots \ldots \ldots \ldots \ldots \ldots$

2. OBJECTIVES AND WORK PLAN $\ldots \ldots \ldots \ldots \ldots \ldots \ldots \ldots \ldots \ldots \ldots, 2$

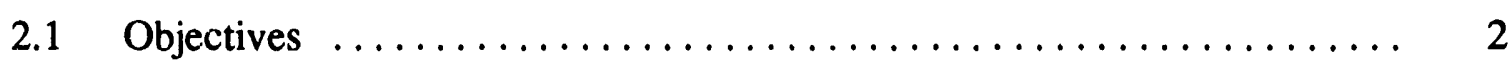

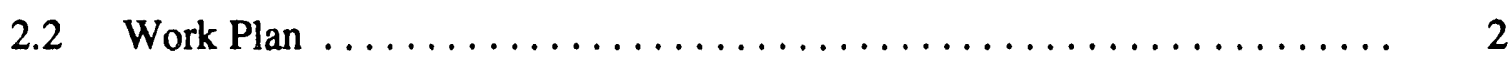

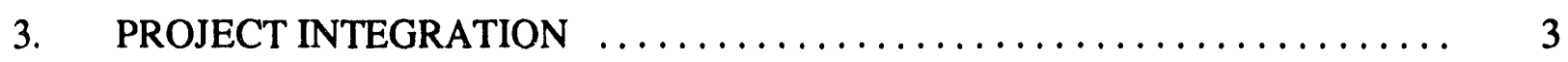

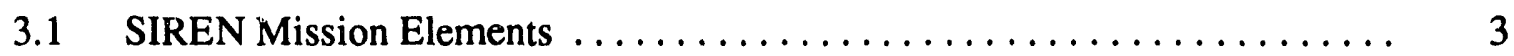

3.2 Debris Analysis of Nuclear Systems $\ldots \ldots \ldots \ldots \ldots \ldots \ldots \ldots \ldots .10$

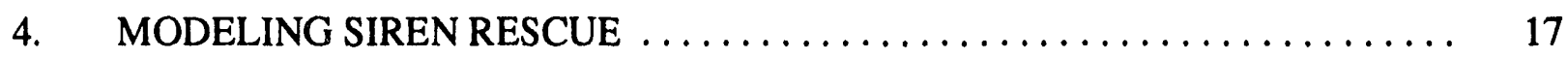

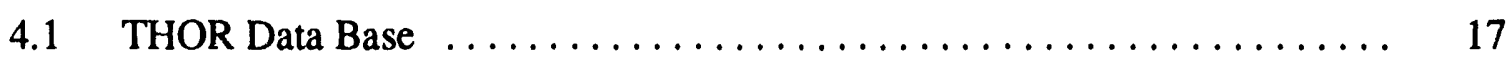

4.2 Mission Scenarios .............................. 17

$4.3 \quad$ Trade Studies $\ldots \ldots \ldots \ldots \ldots \ldots \ldots \ldots \ldots \ldots \ldots \ldots \ldots \ldots, 17$

4.4 Other Features of THOR $\ldots \ldots \ldots \ldots \ldots \ldots \ldots \ldots \ldots \ldots \ldots \ldots, 20$

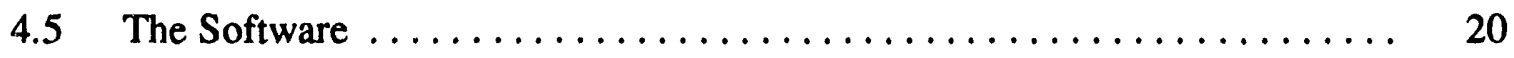

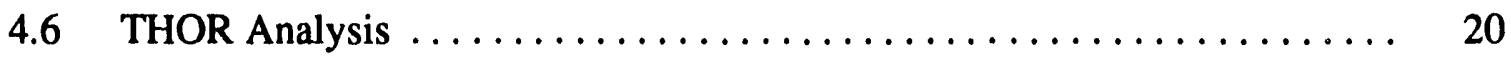

5. INTERNATIONAL IMPLICATIONS OF SIREN $\ldots \ldots \ldots \ldots \ldots \ldots \ldots \ldots, 22$

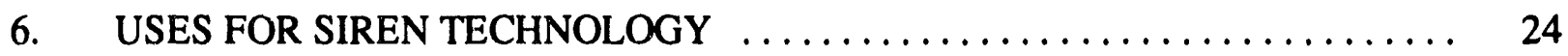

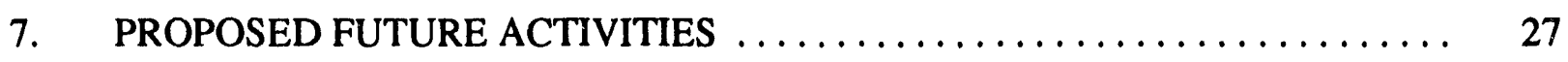

7.1 Completion of the THOR Data Base $\ldots \ldots \ldots \ldots \ldots \ldots \ldots \ldots \ldots, 27$

7.2 Support for International Safety Working Groups $\ldots \ldots \ldots \ldots \ldots \ldots .27$

7.3 Recommendations of Infrastructure and Design Modifications ........ 27

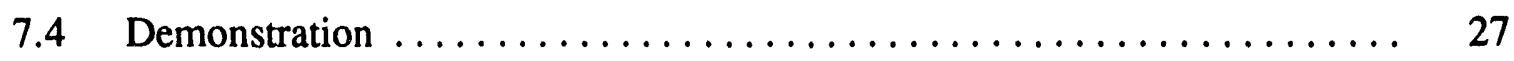

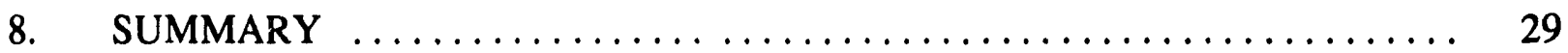

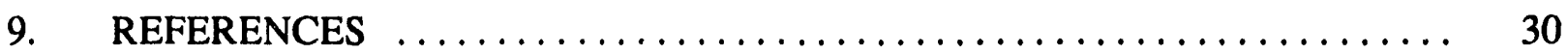




\section{FIGURES}

1.

2.

2. Technology elements of the SIREN concept $\ldots \ldots \ldots \ldots \ldots \ldots \ldots \ldots \ldots \ldots$

3. Conceptual design of a SIREN vehicle . ...................... 9

4. Space surveillance network and field of view at $500 \mathrm{~km} \ldots \ldots \ldots \ldots$

5. Several disposal destinations are achievable from low earth orbit with modest velocity increments $\ldots \ldots \ldots \ldots \ldots \ldots \ldots$

6. Booster mass required to move a spacecraft of mass expected for the SP-100 $\ldots \ldots \ldots 12$

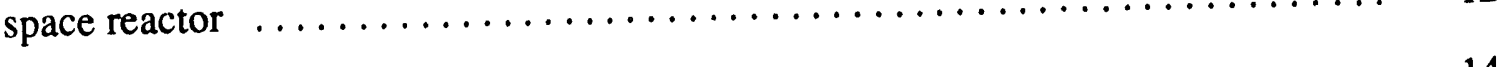

7. Satellite orbits of 36 Russian nuclear powered satellites $\ldots \ldots \ldots \ldots \ldots \ldots$

8. Satellite modeled as an octagonal cross section $\ldots \ldots \ldots \ldots \ldots \ldots \ldots \ldots \ldots$

9. Sample impact data from debris and micrometeoroids $\ldots \ldots \ldots \ldots \ldots \ldots$

10. Sample extended debris data ......................... 15

11. Elements of THOR software package $\ldots \ldots \ldots \ldots \ldots \ldots \ldots \ldots \ldots \ldots \ldots$

12. SIREN supports wide range of missions $\ldots \ldots \ldots \ldots \ldots \ldots \ldots \ldots \ldots \ldots$

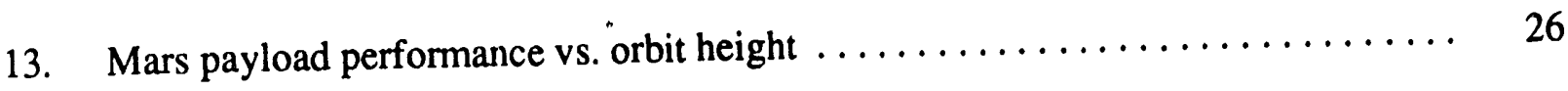

\section{TABLES}

1. Summary of space nuclear power systems launched by U.S. $\ldots \ldots \ldots \ldots \ldots$

2. Summary of space nuclear power systems launched by USSR $\ldots \ldots \ldots \ldots$

3. Reentries of nuclear power sources $\ldots \ldots \ldots \ldots \ldots$

4. Years to definite impact $(0 \%$ growth $/ 5 \%$ growth $) \ldots \ldots \ldots \ldots \ldots \ldots \ldots$

5. Technology options in THORbase $\ldots \ldots \ldots \ldots \ldots \ldots \ldots \ldots \ldots \ldots$ 


\section{Summary Report on Project SIREN (Search, Intercept, Retrieve, Expulsion, Nuclear)}

\section{PURPOSE AND BACKGROUND}

Nuclear systems are key to the success of many space missions. For example, the Apollo science packages, Viking Mars landers, and Pioneer and Voyager planetary fly-bys all were powered by radioisotope generators. There is always a concern that nuclear materials will reenter the biosphere from an aborted nussion, despite onboard safety mechanisms. This has happened for both radioisotope and reactor power systems.

Prior to operation of a nuclear reactor power system, the radiation levels are sufficiently low and not an environmental hazard. A major element of all space reactor safety programs (U.S., Soviet, and others) is to guarantee that once operated at power, a space reactor core can be kept from reentering the terrestrial biosphere. However, reviewing past space reactor experience, notably that of low altitude Soviet space reactors, reveals that attempts to boost a space reactor from low altitude to a higher, long-lived disposal orbit is not always successful.

Considering the evolving, sophisticated space infrastructure projected for the next decade and beyond, we must define a multipurpose space system which provides additional assurance that components of space systems (i.e., space debris, including nuclear systems) never unintentionally return to the Earth's biosphere. Project SIREN seeks to define the overall space infrastructure necessary to find, capture, and dispose of space nuclear power systems in distress. Drawing on emerging space technologies, Project SIREN will also support a variety of other important space debris management missions, creating a greater public confidence in our continued use of advanced technologies in space.

Project SIREN was initiated by the Strategic Defense Initiative Organization (SDIO) in 1989. Project SIREN participants included the Idaho National Engineering Laboratory (INEL) to provide overall project management and integration, with technical support by Science Applications International Corporation (SAIC) and POD Associates, Inc. 


\section{OBJECTIVES AND WORK PLAN}

\subsection{Objectives}

The prime objective of Project SIREN was to define a space technology infrastructure that supports the timely location, acquisition, transportation, and disposal of nuclear power sources in space, thereby preventing them from reentering the biosphere. ${ }^{\text {a }}$ Specific objectives included:

- Identification of options for permanently disposing of spent space reactors, or in case of a premature shutdown, avoiding return to the biosphere

- Identification of needed additions and modifications to the existing or planned space infrastructure and implementation of such a program, if desired

- Computer modeling of SIREN rescue scenarios

- Investigation of the legal implications of such efforts and evaluation of the need for international cooperation in this area.

- $\quad$ Consideration of how SIREN technology might be applied to the broader issues of managing space debris.

\subsection{Work Plan}

The work plan for this project was divided into the following technical tasks: (a) project Integration, (b) modeling SIREN rescue, (c) international Implications of SIREN, and (d) uses for SIREN technology.

a. Letter from Michael D. Braydich, Aerospace Power Division, Wright Patterson Air Force Base, Ohio, to Joe Lee, DOE Idaho Field Office, Idaho Falls, January 16, 1991. 


\section{PROJECT INTEGRATION}

Nuclear-powered systems have been used by the U.S. and USSR in many successful missions (see Tables 1 and 2). However, a number of missions have been aborted. A list of nuclear-powered systems that have reentered the biosphere is provided in Table 3.

Recent national studies support the need for nuclear power for lunar bases, Mars expeditions and surface bases, interplanetary transportation systems, deep solar system exploration missions, large-scale Earth-orbiting civilian platforms, and defense missions. When used at sufficiently high orbits, the radioactive fission products created in the operation of such space nuclear reactors can decay by natural processes to insignificant levels prior to any atmospheric reentry of the aerospace system centuries or millennia later. However, there are other important space missions that will require the start of reactor operations while the aerospace system is still at orbits lower than those considered sufficiently high to accommodate fission product decay. A chemical booster has been incorporated into these lower altitude satellites. Unfortunately, as shown by operational experience (i.e., COSMOS 954 and 1402), these booster mechanisms can fail. Furthermore, it may not always be desirable to incur the mass-penalty associated with an onboard booster system. Project SIREN is being investigated as an external, independent means to capture and expel spent or distressed aerospace nuclear sources under circumstances that could arise with the expanded use of nuclear power systems in space in the next century.

\subsection{SIREN Mission Elements 1,2}

The elements of a SIREN mission are presented in Figure 1 and illustrated in Figure 2. These include (a) tracking facilities to locate the satellite with nuclear materials aboard, (b) a maneuverable SIREN vehicle, (c) means to capture the target satellite, (d) means to separate the nuclear materials from the remainder of the satellite, (e) disposal mechanisms, (f) means to disengage and recover the SIREN vehicle, and (g) means to assess that successful disposal has occurred. A conceptual design of a SIREN vehicle is given in Figure 3. It includes propulsion for intercepting the target satellite, maneuvering in the vicinity of the satellite, and recovering the SIREN vehicle. A number of sensors are mounted on the satellite for inspection and operation of teleoperated devices. Also illustrated is a mechanism for capturing the target satellite. It is assumed that the satellite to be captured is spinning; capture methods must take into account that the target satellite is noncooperative and radioactive. The SIREN vehicle also incorporates teleoperated devices for detaching the nuclear materials. This detachment reduces the mass of the disposed material. Disposal rockets must be attached to the nuclear materials for removal to higher orbit or other locations away from Earth. Support systems (e.g., command and control, power supplies, communications) are also on the SIREN vehicle.

The system is designed to recover the SIREN vehicle. Whether it should be ground- or space-based depends on the space infrastructure in existence at the time and the inclinations of the target satellites of interest. A major consideration in the formulation of the SIREN system is the ability to modify and repeat the operations if not completely successful. If there is a failure to successfully dispose of the nuclear materials, this external system permits multiple tries until success is achieved.

The tracking system can take advantage of the Space Surveillance Network, consisting of a network of both radar and optical sensors. The radars are used for detection and tracking of objects in both low Earth orbit and geosynchronous orbit. The optical systems, such as the Air Force Maui Optical Station located on the island of Maui, Hawaii, can be used for detection and tracking of objects in high Earth orbit, as well as to determine rough physical characteristics of objects in space (see Figure 4). 
Table 1. Summary of space nuclear power systems launched by U.S.

\begin{tabular}{|c|c|c|c|c|}
\hline Power Source & Spacecraft & Mission Type & Launch Date & Status \\
\hline SNAP-3B7 & TRANSMIT 4A & Navigational & June 29,1961 & $\begin{array}{l}\text { RTG operated for } 15 \text { years. } \\
\text { Satellite now shutdown but } \\
\text { operational. }\end{array}$ \\
\hline SNAP-3B8 & TRANSIT 4B & Navigational & November 15,1961 & $\begin{array}{l}\text { RTG operated for nine years. } \\
\text { Satellite operation was intermittent } \\
\text { after } 1962 \text { high-altitude nuclear } \\
\text { test. Last reported signal in } 1971 .\end{array}$ \\
\hline SNAP-9A & TRANSIT 5-BN-1 & Navigational & September 2, 1963 & $\begin{array}{l}\text { RTG operated as planned. Non- } \\
\text { RTG electrical problems on } \\
\text { satellite caused satellite to fail } \\
\text { after nine months. }\end{array}$ \\
\hline SNAP-9A & TRANSIT 5-BN-2 & Navigational & December 5, 1963 & $\begin{array}{l}\text { RTG operated for over six years. } \\
\text { Satellite lost navigational } \\
\text { capability afterer } 1.5 \text { years. }\end{array}$ \\
\hline SNAP-9A & TRANSIT $5-\mathrm{BN}-3$ & Navigational & April $21, \quad 1964$ & $\begin{array}{l}\text { RTG operated as planned. } \\
\text { Mission was aborted because of } \\
\text { launch vehicle failure. }\end{array}$ \\
\hline $\begin{array}{l}\text { SNAP-10A } \\
\text { (Reactor) }\end{array}$ & Snapshot & Experimental & April 3, 1965 & $\begin{array}{l}\text { Reactor operated successfully as } \\
\text { planned. Satellite shutdown } \\
\text { reactor after } 43 \text { days. }\end{array}$ \\
\hline SNAP-19B2 & Nimbus-B-1 & Meteorological & May 18,1968 & $\begin{array}{l}\text { RTGs operated as planned. } \\
\text { Mission was aborted because of } \\
\text { range safety destruct. RTGs } \\
\text { recovered. }\end{array}$ \\
\hline SNAP-19B3 & Nimbus III & Meteorological & April 14, 1969 & $\begin{array}{l}\text { RTGs operated for over } 2.5 \text { years } \\
\text { (no data taken after that). }\end{array}$ \\
\hline SNAP-27 & Apollo 12 & Lunar & November 16, 1969 & $\begin{array}{l}\text { RTG operated for above eight } \\
\text { years (until station was shutdown). }\end{array}$ \\
\hline SNAP-27 & Apollo 13 & Lunar & April 11, 1970 & $\begin{array}{l}\text { Mission aborted on way to moon. } \\
\text { Heat source returned to South } \\
\text { Pacific Ocean. }\end{array}$ \\
\hline SNAP-27 & Apollo 14 & Lunar & January 31,1971 & $\begin{array}{l}\text { RTG operated for about } 6.5 \text { years } \\
\text { (until station was shutdown). }\end{array}$ \\
\hline SNAP-27 & Apollo 15 & Lunar & July 26,1971 & $\begin{array}{l}\text { RTG operated for over six years } \\
\text { (until station was shutdown). }\end{array}$ \\
\hline SNAP-19 & Pioneer 10 & Planetary & March 2, 1972 & $\begin{array}{l}\text { RTGs still operating. Spacecraft } \\
\text { successfully operated to Jupiter } \\
\text { and is now beyond orbit of Pluto. }\end{array}$ \\
\hline
\end{tabular}


Table 1. (continued).

\begin{tabular}{|c|c|c|c|c|}
\hline Power Source & Spacecraft & Mission Type & Launch Date & Status \\
\hline SNAP-27 & Apollo 16 & Lunar & April 16, 1972 & $\begin{array}{l}\text { RTG operated for about } 5.5 \text { years } \\
\text { (until station was shutdown). }\end{array}$ \\
\hline Transit-RTG & $\begin{array}{l}\text { "TRANSIT" } \\
\text { (TRIAD-01-1X) }\end{array}$ & Navigational & September 2, 1972 & RTG still operating. \\
\hline SNAP-27 & Apollo 17 & Lunar & December 7, 1972 & $\begin{array}{l}\text { RTG operated for almost five } \\
\text { years (until station was shutdown). }\end{array}$ \\
\hline SNAP-19 & Pioneer II & Planetary & April 5, 1973 & $\begin{array}{l}\text { RTGs still operating. Spacecraft } \\
\text { successfully operated to Jupiter, } \\
\text { Saturn, and beyond. }\end{array}$ \\
\hline SNAP-19 & Viking I & Mars & August 20,1975 & $\begin{array}{l}\text { RTGs operated for over six years } \\
\text { (until lander was shutdown). }\end{array}$ \\
\hline SNAP-9 & Viking 2 & Mars & September 9, 1975 & $\begin{array}{l}\text { RTGs operated for over six years } \\
\text { until relay link was lost. }\end{array}$ \\
\hline MHW-RTG & LES 8 & Communications & March 14, 1976 & RTGs still operating. \\
\hline MHW-RTG & LES 9 & Communications & March 14, 1976 & RTGs still operating. \\
\hline MHW-RTG & Voyager 2 & Planetary & August 20,1977 & $\begin{array}{l}\text { RTGs still operating. Spacecraft } \\
\text { successfully operated to Jupiter, } \\
\text { Saturn, Uranus, and beyond. }\end{array}$ \\
\hline MHW-RTG & Voyager 1 & Planetary & September 5, 1977 & $\begin{array}{l}\text { RTGs still operating. Spacecraft } \\
\text { successfully operated to Jupiter, } \\
\text { Saturn, and beyond. }\end{array}$ \\
\hline GPHS-RTG & Galileo & Planetary & October 18,1989 & RTG still operating spacecraft. \\
\hline GPHS-RTG & Ulysses & Planetary & October 6, 1990 & RTG still operating spacecraft. \\
\hline
\end{tabular}


Table 2. Summary of space nuclear power systems launched by USSR.

\begin{tabular}{|c|c|c|}
\hline Satellite Deignation & Launch Date & Termination Date \\
\hline $\begin{array}{l}\text { Cosmos } 367 \\
\text { Cosmos } 402 \\
\text { Cosmos } 465 \\
\text { Cosmos } 516 \\
\text { Cosmos } 626\end{array}$ & $\begin{array}{l}\text { October 3, } 1970 \\
\text { April 1, 1971 } \\
\text { Dece.nber 25, } 1971 \\
\text { August 21, 1972 } \\
\text { December 27, } 1973\end{array}$ & $\begin{array}{l}\text { October 8, } 1970 \\
\text { April 1, 1971 } \\
\text { January 3, 1972 } \\
\text { September 22, } 1972 \\
\text { February 9, 1974 }\end{array}$ \\
\hline $\begin{array}{l}\text { Cosmos } 651 \\
\text { Cosmos } 654 \\
\text { Cosmos } 723 \\
\text { Cosmos } 724\end{array}$ & $\begin{array}{l}\text { May } 15,1974 \\
\text { May } 17,1974 \\
\text { April 2, } 1975 \\
\text { April 7, } 1975\end{array}$ & $\begin{array}{l}\text { July } 25,1974 \\
\text { July } 30,1974 \\
\text { May } 15,1975 \\
\text { June } 11,1975\end{array}$ \\
\hline $\begin{array}{l}\text { Cosmos } 785 \\
\text { Cosmos } 860 \\
\text { Cosmos } 861 \\
\text { Cosmos } 952\end{array}$ & $\begin{array}{l}\text { December } 12,1975 \\
\text { October } 17,1976 \\
\text { October 21, } 1976 \\
\text { September } 16,1977\end{array}$ & $\begin{array}{l}\text { December } 12,1975 \\
\text { November } 10,1976 \\
\text { December } 20,1976 \\
\text { October } 7,1977\end{array}$ \\
\hline $\begin{array}{l}\text { Cosmos } 954 \\
\text { Cosmos } 1176 \\
\text { Cosmos } 1249 \\
\text { Cosmos } 1266\end{array}$ & $\begin{array}{l}\text { September 18, } 1977 \\
\text { April 29, } 1980 \\
\text { March 5, } 1981 \\
\text { April 21, } 1981\end{array}$ & $\begin{array}{l}\text { October } 31,1977 \\
\text { September } 10,1980 \\
\text { June } 18,1981 \\
\text { April } 28,1981\end{array}$ \\
\hline $\begin{array}{l}\text { Cosmos } 1299 \\
\text { Cosmos } 1365 \\
\text { Cosmos } 1372 \\
\text { Cosmos } 1402\end{array}$ & $\begin{array}{l}\text { August } 24,1981 \\
\text { May } 14,1982 \\
\text { June } 1,1982 \\
\text { August } 30,1982\end{array}$ & $\begin{array}{l}\text { September } 5,1981 \\
\text { September 26, } 1982 \\
\text { August } 10,1982 \\
\text { December } 28,1982\end{array}$ \\
\hline $\begin{array}{l}\text { Cosmos } 1412 \\
\text { Cosmos } 1579 \\
\text { Cosmos } 1607 \\
\text { Cosmos } 1670\end{array}$ & $\begin{array}{l}\text { October } 2,1982 \\
\text { June } 29,1984 \\
\text { October } 31,1984 \\
\text { August } 1,1985\end{array}$ & $\begin{array}{l}\text { November } 10,1982 \\
\text { September } 26,1984 \\
\text { February } 1,1985 \\
\text { October } 22,1985\end{array}$ \\
\hline $\begin{array}{l}\text { Cosmos } 1677 \\
\text { Cosmos } 1736 \\
\text { Cosmos } 1771 \\
\text { Cosmos } 1818^{a}\end{array}$ & $\begin{array}{l}\text { August } 23,1985 \\
\text { March } 21,1986 \\
\text { August } 20,1986 \\
\text { February } 1,1987\end{array}$ & $\begin{array}{l}\text { October } 23,1985 \\
\text { June } 21,1986 \\
\text { October } 15,1986 \\
\text { July } 1987\end{array}$ \\
\hline $\begin{array}{l}\text { Cosmos } 1860 \\
\text { Cosmos } 1867 a \\
\text { Cosmos } 1900 \\
\text { Cosmos } 1932\end{array}$ & $\begin{array}{l}\text { June } 18,1987 \\
\text { July 10, } 1987 \\
\text { December } 12,1987 \\
\text { March 14, } 1988\end{array}$ & $\begin{array}{l}\text { July } 28,1987 \\
\text { July } 1988 \\
\text { April } 14,1987 \\
\text { May } 19,1988\end{array}$ \\
\hline
\end{tabular}

a. Topaz. 
Table 3. Reentries of nuclear power sources.

Transit 5BN-3 (SNAP 9a generator), 1964.

Nimbus B-1 (SNAP 19 generator), 1968.

RORSAT (?) (nuclear reactor), 1969.

Cosmos 300 and 305 (Po-210 Lunokhod generators), 1969.

Apollo 13 (SNAP 27 generator), 1970.

Cosmos 954 (nuclear reactor), 1978.

Cosnios 1402 (nuclear reactor), 1983.

Cosmos 1900 (nuclear reactor), 1988 (core boosted from $120 \mathrm{~km}$ ).

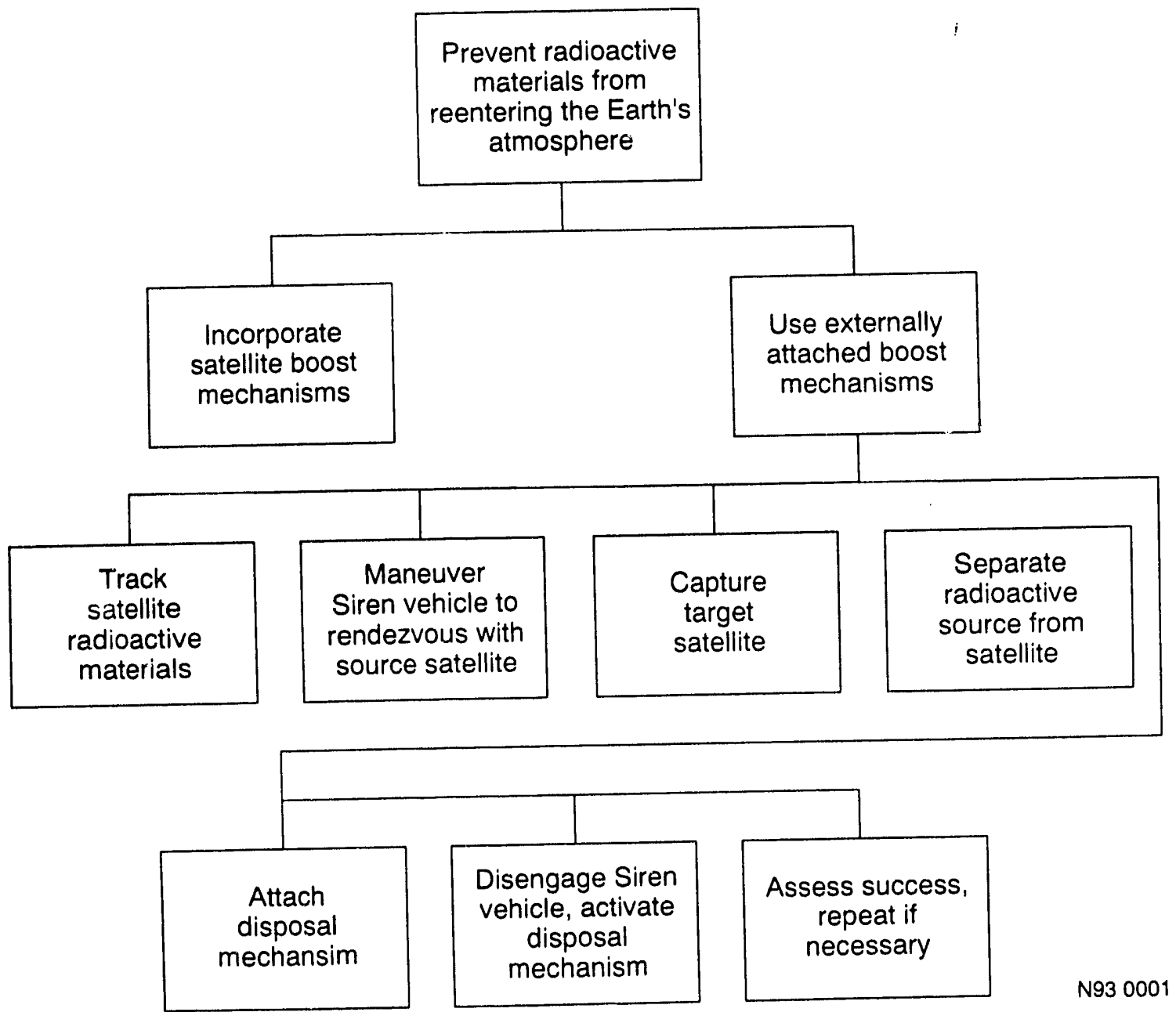

Figure 1. SIREN Goal Tree. 


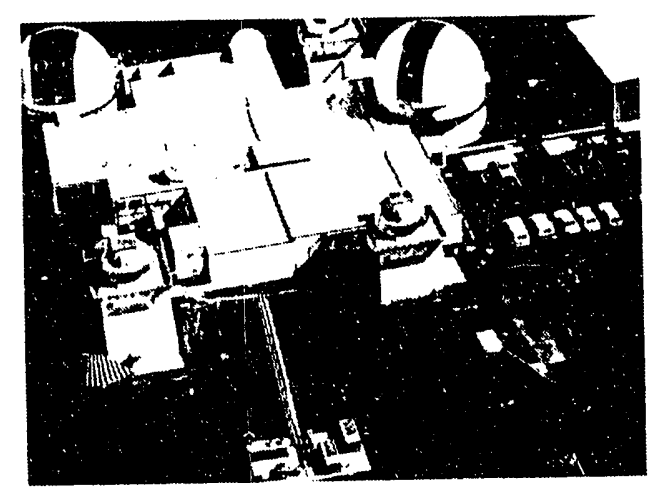

Ground and space based tracking

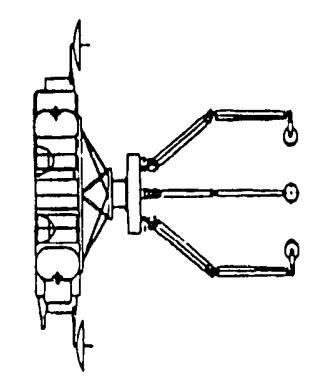

Capture Technologies

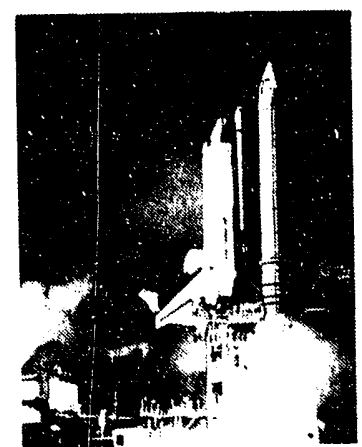

Launch vehicles

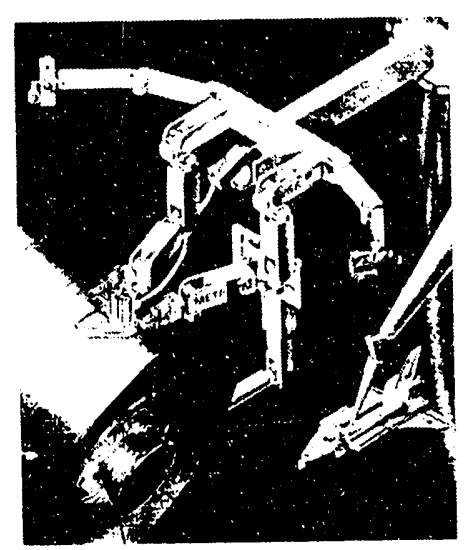

Transport \& Disposal

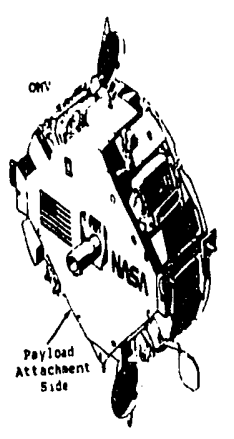

Telerobotics

Figure 2. Technology elements of the SIREN concept. 


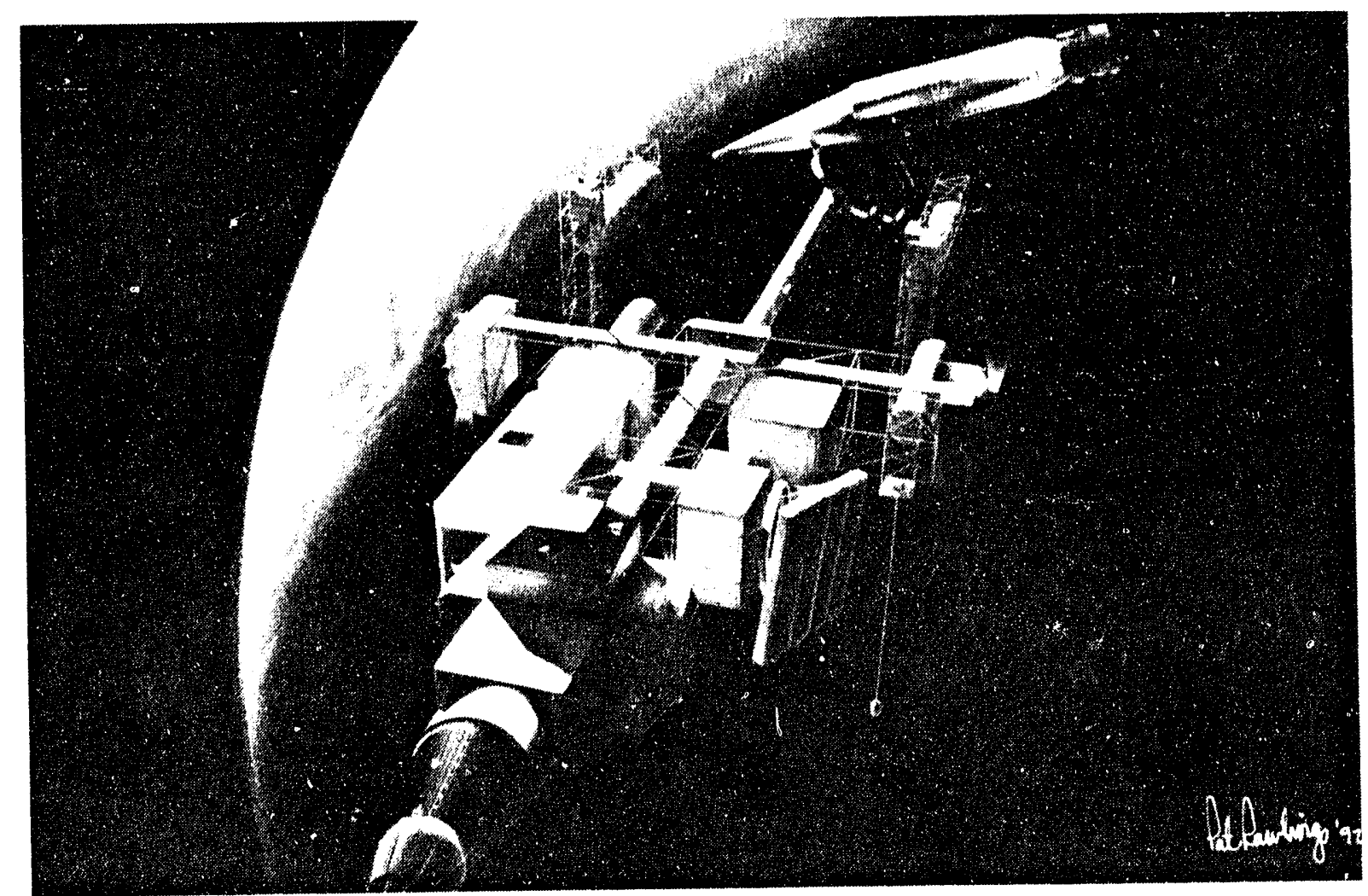

Figure 3. Conceptual design of a SIREN vehicle.

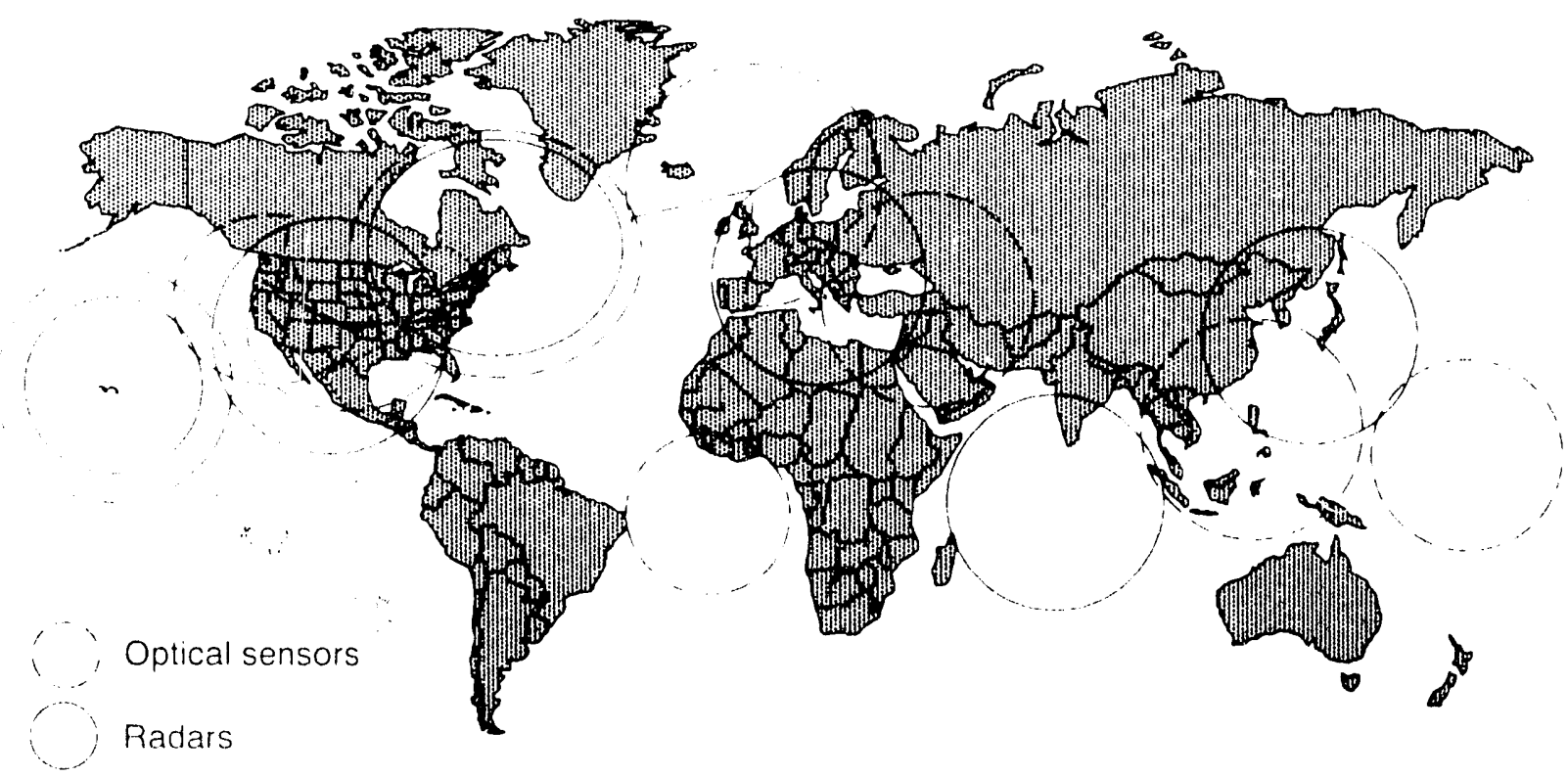

Figure 4. Space surveillance network and field of view at $500 \mathrm{~km}$. 
The SIREN vehicle is based on initial plans for the Orbiting Maneuvering Vehicle (OMV). The vehicle had most of the characteristics necessary to perform the activities associated with maneuvering a vehicle to the vicinity of the nuclear-powered satellite. Also being designed was a Tumbling Satellite Retrieval System as an attachment to the OMV. This attachment was being designed to capture noncooperative satellites that could be tumbling in random orientations. Simulations had been performed to show the feasibility of accomplishing this. Though OMV has been canceled, it provided an understanding of the characteristics to be built into a SIREN vehicle. There is now a planned Rendezvous and Capture Demonstration in 1996 to demonstrate automated space station logistic resupply. $b$ This would demonstrate the needed rendezvous and docking technologies for a SIREN mission. Several vehicles are being proposed as replacements for OMV. These should provide future building blocks for SIREN.

Space Station Freedom has placed emphasis on utilizing robotics for servicing and maintenance. The experience in using such capabilities provides a rich technology heritage for the functions needed in SIREN. For example, the use of telerobotic arms and accompanying sensors previews the function of attaching a rocket booster to the nuclear power system to boost it to a disposal location.

We have not identified any programs that are designed to perform the functions required to detach a nuclear power source from the remainder of the satellite. Explosives, chemical reactions, laser cutting, or mechanical saws are possible approaches. Because the satellite is probably larger than the SIREN vehicle and attachment is at several points, means must be provided to stabilize the satellite as the power system is severed.

There are many acceptable disposal options for space debris (including nuclear materials) other than intentional reentry into the Earth's atmosphere. The choice depends on a variety of factors such as retrieval of materials for future processing in space, cost, and political considerations. Figure 5 provides the velocity increments needed to transfer between points in cislunar space. A series of calculations have been performed to determine the booster mass to move a spacecraft of mass expected for the SP-100 space reactor from a 500-km circular Earth orbit to candidate disposal destinations. These calculations (see Figure 6) were performed for both the reactor system mass $(\sim 3470 \mathrm{~kg})$ and total satellite mass (including heat rejection subsystem and payload) of $5580 \mathrm{~kg}$. Disposal options and results demonstrate that a variety of permanent disposal sites are available to the SIREN program at acceptable transfer masses using existing booster stages.

\subsection{Debris Analysis of Nuclear Systems 3}

Currently, there are over 40 satellites that have nuclear materials onboard in low Earth orbits. Even if no additional nuclear-powered satellites are launched, we still must be concerned with any events that might affect these satellites. For instance, could a nuclear debris belt be formed by the collision of debris or meteoroids with these satellites?

Serious damage can be expected if a satellite collides with either (a) a particle of size greater than 10-cm diameter (space debris or meteorites) or (b) another satellite. However, even smaller particles on the order $1 \mathrm{~cm}$ of could cause ancillary damage, such as safety rod malfunction. The threshold particle size for reactor damage is obviously dependent on the specifics of the design and the point of impact. The time period of concern is about 300 years

b. Telecom with Mike Card, December 21, 1992. 


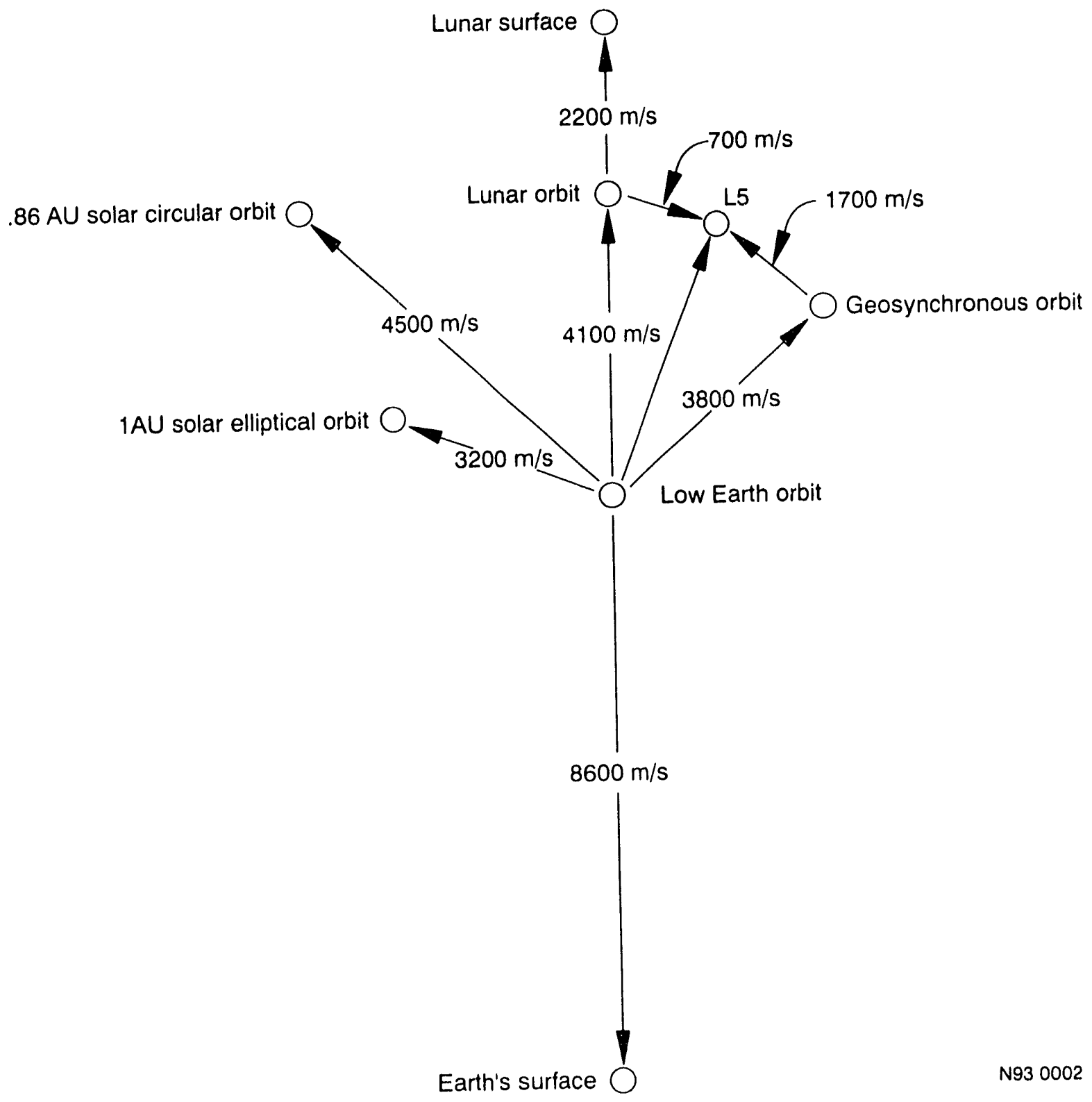

Figure 5. Several disposal destinations are achievable from low earth orbit with modest velocity increments. 


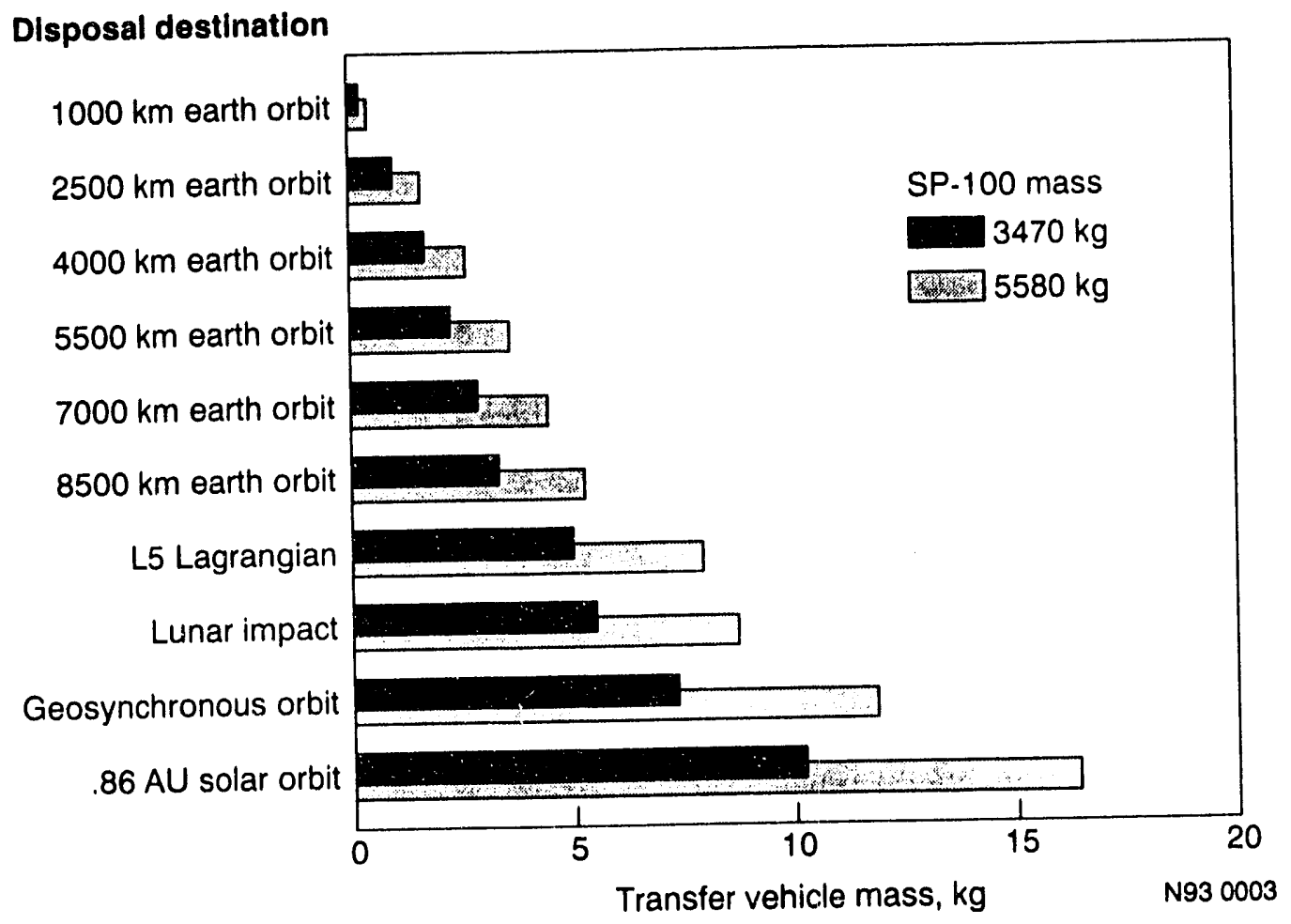

Figure 6. Booster mass required to move a spacecraft of mass expected for the SP-100 space reactor. 
after reactor operation. This is the time for the residual radioactivity to drop to acceptable low levels. It is, therefore, important to guarantee that the mean time interval between possible damaging impacts is very long, or else collision avoidance techniques become necessary.

A study has been made of the frequency of close approaches between 36 Russian nuclearpowered satellites. The orbital data were obtained from the Committee on the Peaceful Uses of Outer Space report to the United Nations General Assembly (90-04895). Figure 7 illustrates the orbits of the satellites. In addition, there are other (nonnuclear) satellites and derelict space objects within the shell volume represented by the altitudes of interest. The damaging component of the space debris needs to include all bodies larger than $10 \mathrm{~cm}$ (and possibly down to $1 \mathrm{~cm}$ ). Natural meteoroids greater than $1 \mathrm{~cm}$ can be neglected as a first order approximation because they produce a smaller impact flux than the manmade items.

The POD Associates, Inc., Space Environment (SPENV) code was utilized to generate impact data as a function of micrometeoroids, debris size, and orbital location. The environmental parametric space included particle sizes of 0.001 to $50.0 \mathrm{~cm}$ and three orbits representing typical U.S. and Soviet nuclear reactor destinations: $900-$ and $1000-\mathrm{km}$ altitudes at 65-degree inclination (COSMOS) and 1300-km altitude at 111-degree inclination (SNAP-IOA).

The satellite was modeled as an octagonal cross-section, as illustrated in Figure 8. Seven sets of impact data were generated by each SPENV run for all unique satellite directions: RAM, 45 degrees from the RAM velocity vector (Side A), 90 degrees from RAM (Side B), 135 degrees from RAM (Side C), trailing edge, (Trail), Earth facing (Earth), and space facing (Space). For the accumulation of impacts unique to each direction, the satellite model was neither tumbled nor rotated.

The above parametric space was used to calculate impact densities as accumulated over 10-, 20- and 50-year periods. Figure 9 is a typical plot showing the debris and micrometeoroid data for the $1000-\mathrm{km}$ orbit, RAM direction and 50 -year accumulation period for no $(0 \%)$ debris growth, and 5\% escalation in the debris and the micrometeoroids. As can be qualitatively observed, the linear 5\% escalation of debris population causes a noticeable growth in the areal impact densities of the larger-sized debris. It should be noted that the $5 \%$ linear growth is put forth by the Kessler debris model ${ }^{4}$ based on predictions of future launch activities.

To better quantify debris escalation over time, data identical to those above were generated for the next 75 years. The number of hits on the RAM vector are cited here because this surface comprises the highest percentage (e.g., 75\% for a cubical satellite) of all hits on the satellite for an orbital inclination of 65 degrees. These RAM data were organized to illustrate the impact areal density as a function of time for the larger debris sizes of $1,5,10$ and $50 \mathrm{~cm}$. Figure 10 shows the impact areal density as a function of time for the RAM surface and for particles greater than $10 \mathrm{~cm}$. Assuming 50 nuclear satellites, each with a RAM surface area of $78.5 \mathrm{~m}^{2}$, the figure shows the probability of a collision on any satellite by the horizontal line. The interception points of this line and the two growth curves determine when this guaranteed collision occurs for a given number of satellite impacts per square meter. We see that for zero growth, a collision will occur by 2031 (within 40 years), whereas, for the 5\% growth, the collision will occur by 2021 (within 30 years).

Table 4 contains a summary of the number of years to definite impact for the scenarios addressed in this study for both growth rates. 


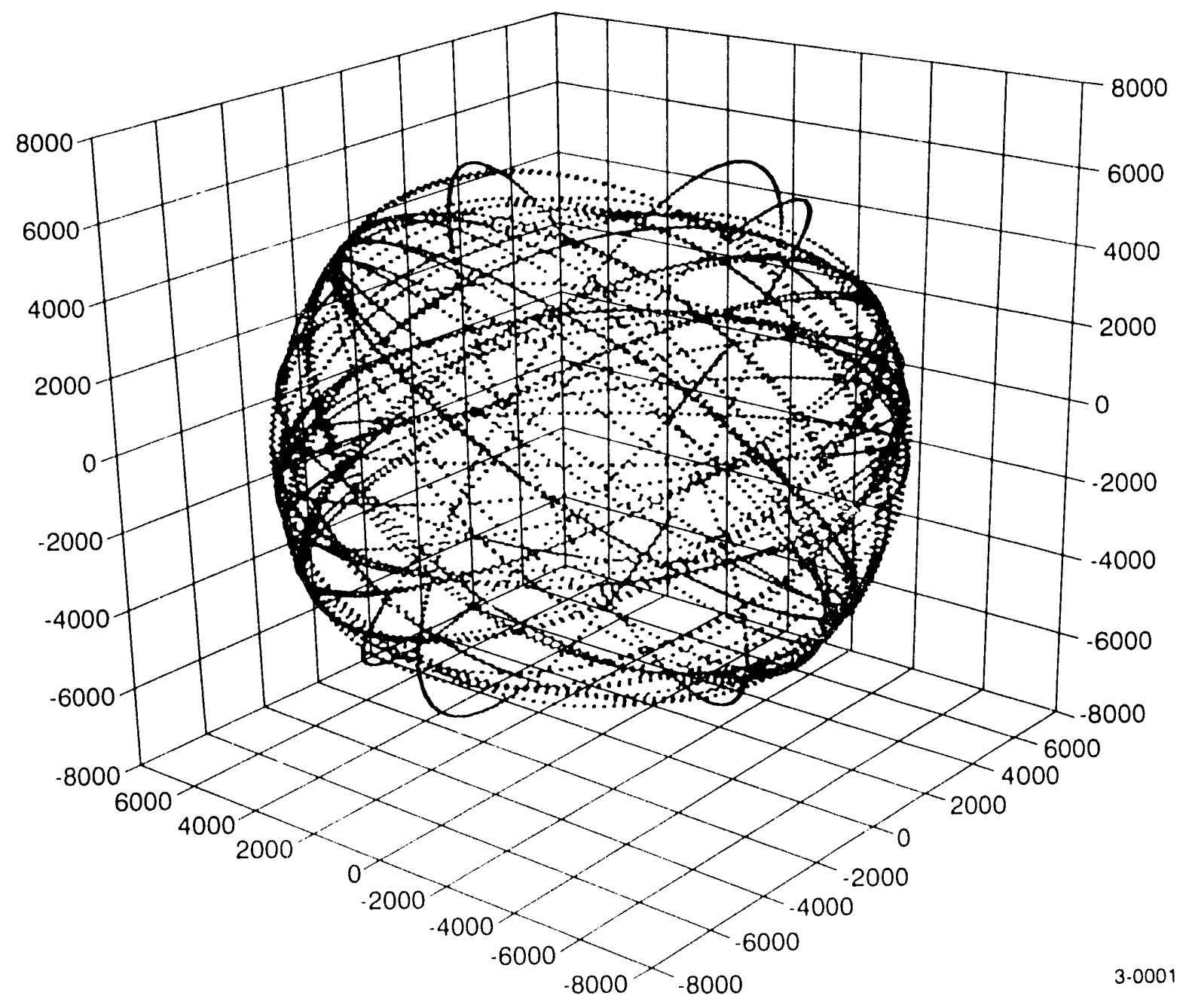

Figure 7. Satellite orbits of 36 Russian nuclear powered satellites.

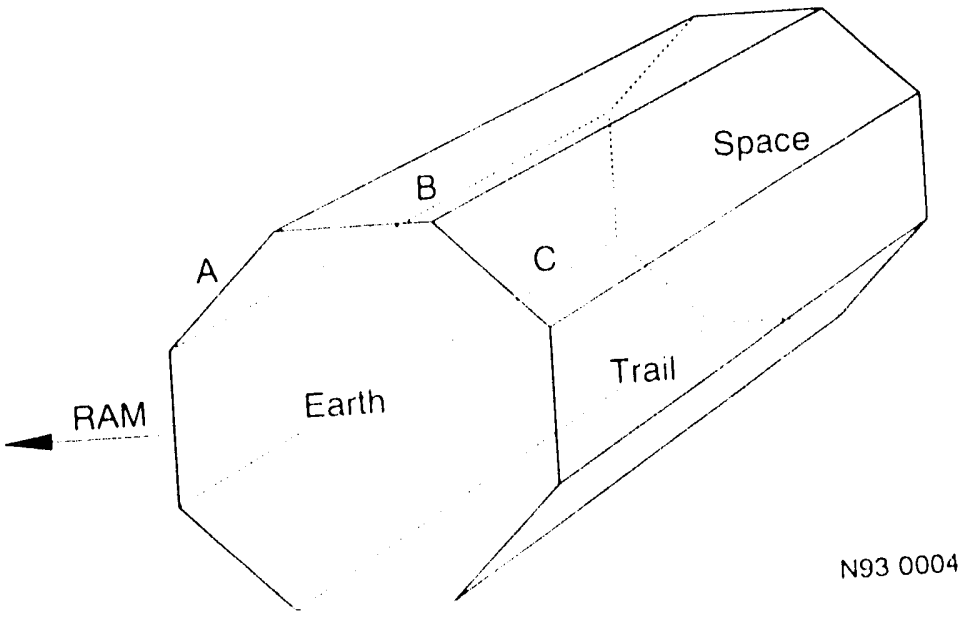

Figure 8. Satellite modeled as an octagonal cross section. 


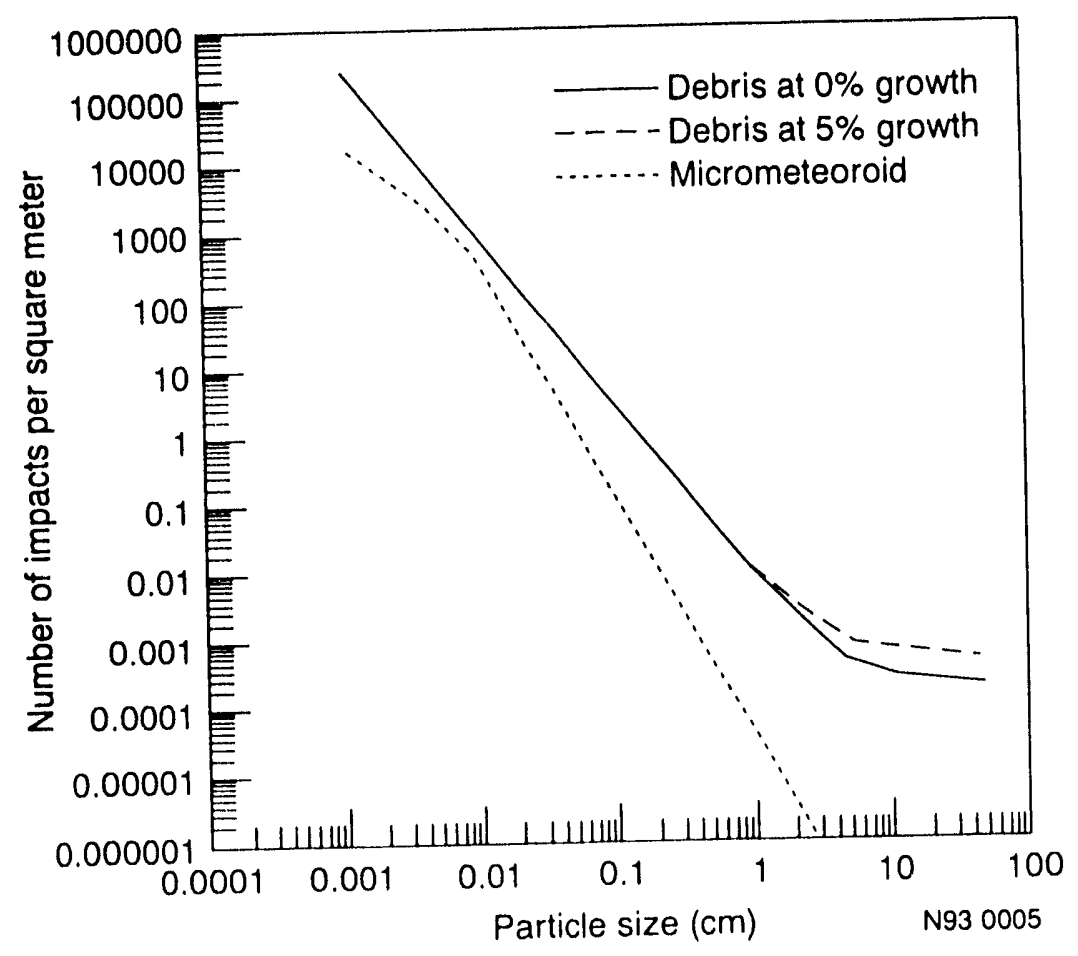

Figure 9. Sample impact data from debris and micrometeoriods.

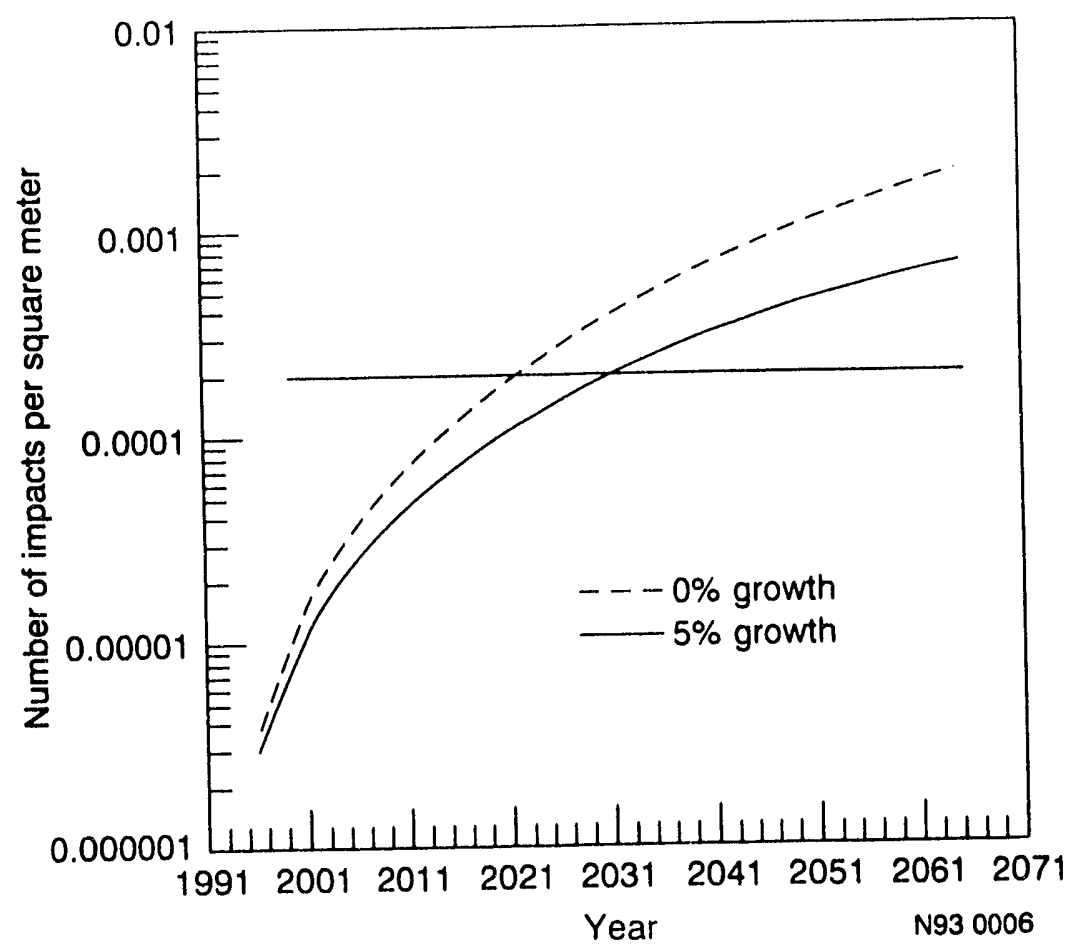

Figure 10. Sample extended debris data. 
Table 4. Years to definite impact (0\% growth/5\% growth).

\begin{tabular}{lllll}
\hline & \multicolumn{4}{c}{ Size of Object } \\
\cline { 2 - 5 } Satellite Orbit & $1.0 \mathrm{~cm}$ & $5.0 \mathrm{~cm}$ & $10.0 \mathrm{~cm}$ & $50.0 \mathrm{~cm}$ \\
\hline $900 \mathrm{~km} / 65$ degrees & $9 / 9$ & $34 / 28$ & $41 / 30$ & $50 / 35$ \\
$1000 \mathrm{~km} / 65$ degrees & $9 / 9$ & $33 / 26$ & $39 / 29$ & $48 / 34$ \\
$1300 \mathrm{~km} / 111$ degrees & $16 / 16$ & $60 / 46$ & $74 / 50$ & $\sim 93 / 58$ \\
\hline
\end{tabular}

These results indicate that the likelihood of a nuclear reactor colliding with another reactor for 50 satellites in approximately the same inclination between 800 and $1100 \mathrm{~km}$ is over 700 years. This time drops to 178 years if 100 satellites are considered. The time for approaches within $1 \mathrm{~km}$ is less than 1 month.

The likelihood of a nuclear satellite colliding with other space junk is higher. Evaluation shows that a nuclear satellite residing with the current near Earth population will suffer impact damage from debris approximately $1 \mathrm{~cm}$ diameter within 15 years. Penetrating impact due to debris ranging from 5 to $10 \mathrm{~cm}$ in diameter will occur in the next 25 to 50 years, and catastrophic impact due to debris that is greater than $50 \mathrm{~cm}$ in diameter will occur within 30 to 55 years. Increasing the satellite population at this orbit for disposal will only serve to increase the likelihood of a damaging collision. 


\section{MODELING SIREN RESCUE5}

A data base and mission analysis program has been developed to assess the use of available or projected technologies needed to perform a SIREN mission and the need for additional technology developments. This program, called Technology Hierarchy for Orbital Recovery (THOR), is now operational, though the quantity of technology data incorporated is limited. It is a fully interactive, technology model data base and mission analysis code to identify technologies and missions for candidate SIREN rescues. THOR incorporates innovative and efficient means for performing a range of trade studies for different reactor operating conditions and orbital scenarios. Technologies in the data base include tracking facilities, capture and transfer vehicles, robotics, disposal options, and reactor descriptions. Mission analysis scenarios cover tracking, capture, and disposal. Technology readiness level information is used to assess the availability of a given technology to perform missions on given desired event dates. Trade studies can be performed for a variety of scenarios and parameter spaces.

THOR users define the mission scenario for the trade studies. This consists of choosing the event date for the mission, the level of technology that the user is willing to accept for the particular mission, and the aspects of the mission of user interest. If sufficient technology is not available or if one wants to test iise effects of new technology, a "dummy" technology can be added to the data base. For a given mission, THOR might investigate ten different capture vehicles, six transfer vehicles, eight launch vehicles and two launch facilities for a given nuclearpowered satellite. If all of these techrologies could meet the mission needs, over 3,500,000 combinations would be considered by 'THOR before arriving at a mission design. If only half of the technologies would meet the mission criteria, the combination is 32,000 . By computerizing this process with the methods use 1 in THOR, endless tradeoffs can be made very quickly (in minutes) and accurately.

The elements of THOR are shown in Figure 11 and described below.

\subsection{THOR Data Base}

One component of THOR is the data base (THORbase), which contains detailed technical information on all the technologies that could be used in a reactor retrieval and similar information on the reactor(s). New information can be conveniently added into the data base or the existing information can be edited or deleted. This allows the user to create "dummy" technologies that may not currently exist, but would be needed to accomplish a space reactor disposal mission.

The current data base in THOR is limited because of available funding. Items incorporated within the database are shown in Table 5.

\subsection{Mission Scenarios}

Once the data base of information is established, the user is ready to define an actual mission scenario. This consists of choosing the event date for the mission, the NASA level of technology that the user is willing to accept for this mission, and aspects of the mission in which the user is interested (e.g., tracking, capture, or disposal).

\subsection{Trade Studies}

After determining the mission scenario, the user can set up the trade studies. Here the flexibility of THOR is clearly demonstrated. In the "Trades" area of THOR, the user has the option to narrow or expand the trade space of the study by selecting specific technologies or the 


\begin{tabular}{|c|c|c|c|}
\hline Database & Mission & Irades & Options \\
\hline \multirow{3}{*}{$\begin{array}{l}\text { Power system } \\
\text { Satellite orbit } \\
\text { Tracking sensor } \\
\text { Tracking asset } \\
\text { Tracking facility } \\
\text { Launch vehicle } \\
\text { Launch facillities } \\
\text { Capture technologies } \\
\text { Transfer vehicles } \\
\text { Disposal options }\end{array}$} & $\begin{array}{l}\text { Trade types } \\
\text { Technology level }\end{array}$ & \multirow{2}{*}{$\begin{array}{l}\text { Define mission parameters } \\
\text { View scenario } \\
\text { Load scenario } \\
\text { Run scenario } \\
\text { Save scenario } \\
\text { Print scenario }\end{array}$} & $\begin{array}{l}\text { Interactive } \\
\text { Batch }\end{array}$ \\
\hline & & & $\begin{array}{l}\text { Set defaults } \\
\text { Backup THORbase } \\
\text { Restore THORbase }\end{array}$ \\
\hline & & & \\
\hline REFERENCES & & & \\
\hline
\end{tabular}

Figure 11. Elements of THOR software package.

Table 5. Technology options in THORbase.

Technology Type Technology Description

Power Systems

Payloads

Satellite orbits

Tracking sensors

Tracking assets

Tracking facility

Launch vehicles

Launch facilities

Capture technology

Transfer technologies

Disposal options
TOPAZ-II, SNAP-10A, SP-100

Communications

Various earth orbits

Various including: Conventional visible and infrared imaging, photometer, radiometry, compensated imaging

$1.2 \mathrm{~m} \mathrm{B29}$ telescope, $1.2 \mathrm{~m} \mathrm{B37}$ telescope, $1.6 \mathrm{~m}$ telescope

AMOS (Hawaii)

Shuttle, Titan II, Titan IV

Cape Canaveral, Vandenburg

OMV

Centaur, IUS-2 stage, PAM-IID, TOS, Transtage

Various including: GEO, Lunar landing and orbit, Earth circular, AU solar elliptical 
entire data base. For example, if the user is only interested in determining whether the AMOS facility has the capability to track the SP-100 nuclear reactor at a specific orbital location, the user can select AMOS as the only tracking facility to be considered in the trade study. The same options are given for retrieval (capture, transfer, and launch vehicles) and disposal options (placement of the reactor at a range of orbital locations or one specific orbit such as geosynthronous orbit). The user is also given the opportunity to determine the operational status of the reactor and payload system in terms of the reactor startup and shutoff dates; power level; whether the reactor is operational, intact, stable; if it has a beacon; working instrumentation or communications; and docking features. The orbital parameters for each scenario can also be defined, such as orbital time and date, eccentricity, true anomaly, inclination, and semi-latus rectum. The user can select the power components for disposal depending on whether one wants to dispose of the reactor only, the reactor/radiator only, or the entire power system and payload.

This information is used together with definition of the power system; payload; orbital parameters for the power/payload system; and the specific tracking, capture, and disposal options. Once a scenario has been created, the user can run that scenario (or the scenario of choice that has been previously created and saved in a file) in a mission design or technology option mode.

For a mission design, an ephemeris code is first run to put the reactor system in orbit as a function of time, beginning at the event date. Then the capabilities of each of the tracking facilities in the data base are queried to check if the facility and its assets can determine the location and status of the reactor system. It is also determined how of ten the facility can see the reactor. Those facilities are then output with the figures of merit (FOMs) for each facility. An example of FOMs include tracking facilities, the technology readiness level of the facility, the facility location, the detectors and method used to see the reactor, the date of the first sighting, and how often the facility can view the reactor are determined. If the facility is not operational (indicated by its technology readiness level), then the cost and time to bring the facility to that point is output. Based on these FOMs, the user can select a facility for this mission. Next THOR determines the capture vehicle(s) that can retrieve the reactor and once again outputs the FOMs for these vehicles. This allows the user to select a capture vehicle for the mission. This same process continues for the transfer and launch vehicle, launch sites, and disposal options where the user is given technologies that can accomplish this mission and the user selects the technologies for their mission based on the given FOMs. During this mission design, the user also has the opportunity to receive information on technology holes. Technology holes arise when the technology is not available for a particular scenario. The user is able to display information on why the hole occurred and can then, if desired, use this information to modify and rerun a scenario. The final information displayed in a mission design is a set of screens that summarizes the mission design and all of its associated parameters.

THOR output identifies the full feasibility of performing a disposal mission from tracking to disposal. A fully implemented THOR data base will allow this to take place in a very quick time frame (in hours) with optimized output in terms of mission feasibility, mission hardware, time-frame, and cost.

As an example of the operation of THOR, consider a COSMOS 1900-type situation. THOR would be implemented starting with the definition of the reactor's initial physical and orbital characteristics. Then, THOR's intrinsic ephemeris and tracking models would be utilized in conjunction with the THORba'se (THOR technology and reactor data base) to:

- Identify an estimated ieentry date and ground track for COSMOS

- Identify the tracking facilities that have the capability to acquire and track COSMOS 
- Identify off-the-shelf technologies that could be used to capture COSMOS

- Identify the total integration and lead time necessary to conduct a successful SIREN mission for COSMOS

Iaentify a range of COSMOS disposal options and the merits of each one

Project the cost of a SIREN capture and disposal mission for COSMOS.

\subsection{Other Features of THOR}

THOR is being developed with many other features including an on line "Help" menu with information on the cperation and description of the elements of THOR. Other options will include the ability to run THOR in either a screen interactive (the mission design) or batch (technology options) mode in order to allow multiple scenario runs. Also, if the user is not interested in conducting a mission desizn for a particular reactor rescue, he or she can choose to output "technology options," which describe the general technology availability for a given reactor mission scenario.

\subsection{The Software}

THOR is completely interactive and designed to be user friendly. THOR runs on a PC 286 or 386 machine in the windows envir nnment. The data base software is Superbase 4 by Precision Software. The modularity and flexibility of THOR permits data to be used from other data base programs. A large variety of graphical tools to create images are available. This is useful for showing pictures of the technologies and a graphical representation of a mission. For the trade studies, pictures of the different nuclear reactors and their payloads are shown. In choosing an orbit for the reactor, an orbital pictorial guide is displayed with a description of the orbital technologies.

\subsection{THOR Anaiysis}

To perform an analysis of a mission, such as the inspection and boost of the Transit (TRIAD-01-0X) satellite launched in 1972 with an apogee of $838 \mathrm{~km}$ and perigee of $742 \mathrm{~km}$ (projected orbital life of 150 years), 6 one would first insert into the data base a description of the power system and payload. Currently, the data base includes descriptions of SNAP-10A, Topaz II, and SP-100. The data to be inserted include the technology readiness, dates for technology
level of interest, references, number of components, mass, volume, g-load limits, dimensions moment of inertia, reluctance, radar signature, power level, neutron and gamma fluxes, radiator temperature, mass and volume, communications, and manufacturer. The standard payload description is for a communication satellite. Information on the particular satellite of interest can be entered. THOR has various tri ing assets and facilities such as telescopes and radars at AMiOS and Jim's Tracking. The prc $c_{c}$ 'm will compute the ability of these tracking facilities to locate the Transit satellite and tell you ow often it can be viewed from each of the locations. For a capture and boost mission, THOR vill then compute the launch vehicles that can be used either out of Kennedy or Vandenburg launch facilities. Currently, the program incorporates the Space Shuttie, Titan II and IV launch vehicles; and Centaur, IUS, PAM IID, TOS, and Transtage transfer vehicles. Various orbital disposal options are included from higher Earth orbits, geosynchronous and five times geosynchronous, to circular solar orbit, solar elliptical and solar impact, and lunar orbit or surface. Technology status are projected for each part of the mission. 
The result will be a description of options that can boost the Transit satellite to the new disposal location based on the date the mission is desired. If no options are available, one can insert projected technologies to identify what is needed to perform the mission. Or one can evaluate the different launch vehicle needs based on the disposal mode. 


\section{INTERNATIONAL IMPLICATIONS OF SIREN}

Project SIREN has international implications because of the concerns of the international community about nuclear materials randomly reentering the biosphere. For instance, the Emergency Preparedness for Nuclear-Powered Satellites Meeting sponsored by the Organization for Econornic Cooperation and Development Nuclear Energy Agency and Swedish National Institute of Radiation Protection in Stockholm, Sweden, in 19899 discussed planning and preparedness for nuclear satellite emergencies, international cooperation in this field, and developing technical guidance. Because SIREN is an external means of disposal of nuclearpowered systems which avoids reentry, it offers a natural means to satisfy much of the international community's concerns.

Part of the SIREN work statement was to lead international technical efforts relative to disposal of reactors in space. During the 9th Symposium on Space Nuclear Power Systems in Albuquerque, New Mexico, on January 13, 1992, an informal meeting was hold with representatives of the former Soviet Union to discuss potential interest in participating in the development of means to prevent radioactive materials from reentry into the atmosphere. Those in attendance included:

- Dr. Nikolai N. Ponomarev-Stepnoi (President of the USSR NS)

- Dr. Vladimir A. Pavshoock (Head of Division, I. V. Kurchatov Institute of Atomic Energy)

- Dr. Veniamine A. Usov (Director, Power Technologies Scientific Production)

- $\quad$ Mikhail Nikitin (USSR Interpreter)

- David Buden (EG\&G Idaho)

- Dr. Joseph Angelo, Jr.(Science Applications International Corp.)

- Dr. Thomas Albert (Science Applications International Corp.)

- Samantha Lapin (POD Associates, Inc.)

- Pat Rawlings (Science Applications International Corp.)

- Yash Holbrook (Interpreter, Science Applications International Corp.)

After presentations on the SIREN project, Dr. Ponomarev-Stepnoi made the following observations:

- Initially, he thought it was too early for a SIREN project. However, he changed his mind and believes that this is the proper time to begin such an activity. He recognizes the need to develop disposal devices for the power systems and that this should be a parallel development effort. He feels it would help to prepare the public to accept the use of nuclear power systems in space.

- There should be public discussion of the SIREN concept. The discussion can initiate broad range participation and acceptance of the public in the development and use of nuclear systems in space. 
- There is definite interest in keeping space cleaner after Cosmos 954.

- International standards for all nuclear reactors should be formulated. The standards would facilitate the disposal of nuclear systems in case of an abort, but compliance would be voluntary.

- The THOR data base should incorporate Soviet systems data, such as Topaz.

The Russians proposed that a followup meeting be held in Russia. However, SDIO requested that further activities with the Russian Federation be discontinued until U.S. government policy could be formulated and that U.S. Department of Energy (DOE) can take the lead in this area. Subsequently, in meetings between DOE and the Russians, ${ }^{c}$ the Russians prepared a written proposal that a U.S./Russian Federation safety working group be formed. A proposed agenda item by DOE is to include external disposal of space nuclear systems.

c. Proposal by the Ministry of Atomic Energy during Interagency fact-finding mission to the former Solviet Union, Moscow, and St. Petersburg, Russia, October 19-28, 1992. 


\section{USES FOR SIREN TECHNOLOGY}

SIREN can support a wide range of missions in low Earth Orbit that are of common interest to the Department of Defense (DoD), National Aeronautics and Space Administration (NASA), and DOE (see Figure 12). So far, we have been discussing SIREN's primary mission, the prevention of radioactive materials from reentering into the biosphere. SIREN can also be used to prevent nuclear debris belts from being formed by remedial actions.

Since 1978, the United Nations has been developing a consensus on the use of nuclear power in Earth orbit. A SIREN capability can form the basis for international cooperation in this field in place of the combative attitude that now exists. SIREN can also enhance public awareness and acceptance of the use of nuclear systems in space.

Satellite servicing and maintenance will eventually become a major activity in space. The same systems needed for the SIREN project can be used for these purposes.

SIREN can support NASA's space exploration plans for the Moon and Mars by making it possible to start the missions safely from lower Earth orbits. As shown in Figure 13, this is important in reducing the cost of these missions. If an abort does occur, SIREN can be used as a repair vehicle. Also, planetary science missions, which might use nuclear electric or nuclear thermal propulsion, can use SIREN as a safety system.

Defense missions can take advantage of SIREN by using it for retrieval and servicing of satellites in low orbits. It also provides a backup safety system for orbit transfer vehicles and satellites with nuclear power plants.

The DOE can also use SIREN as a means to enhance the safety of systems with nuclear power plants in low Earth orbit. 


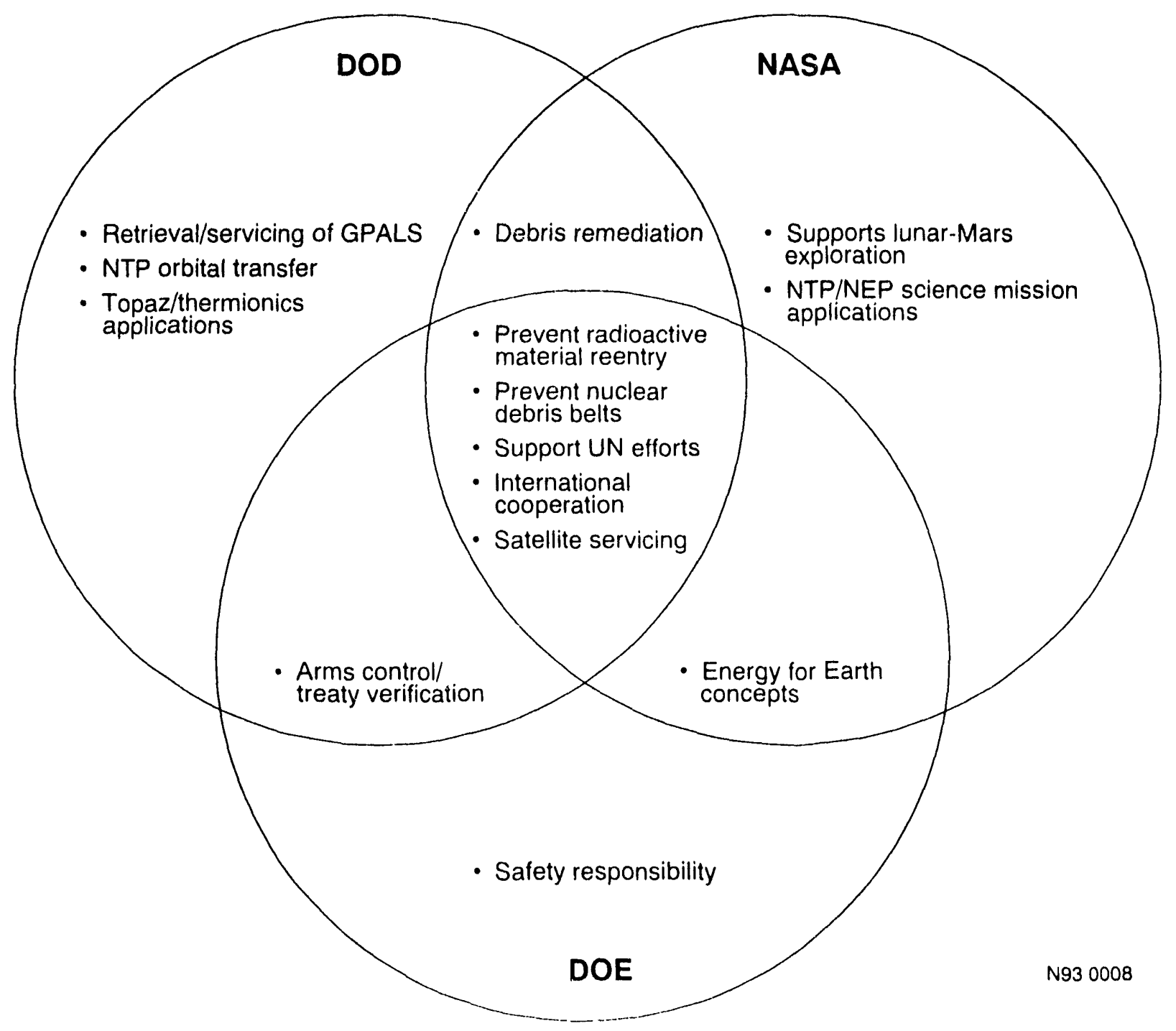

Figure 12. SIREN supports wide range of missions. 


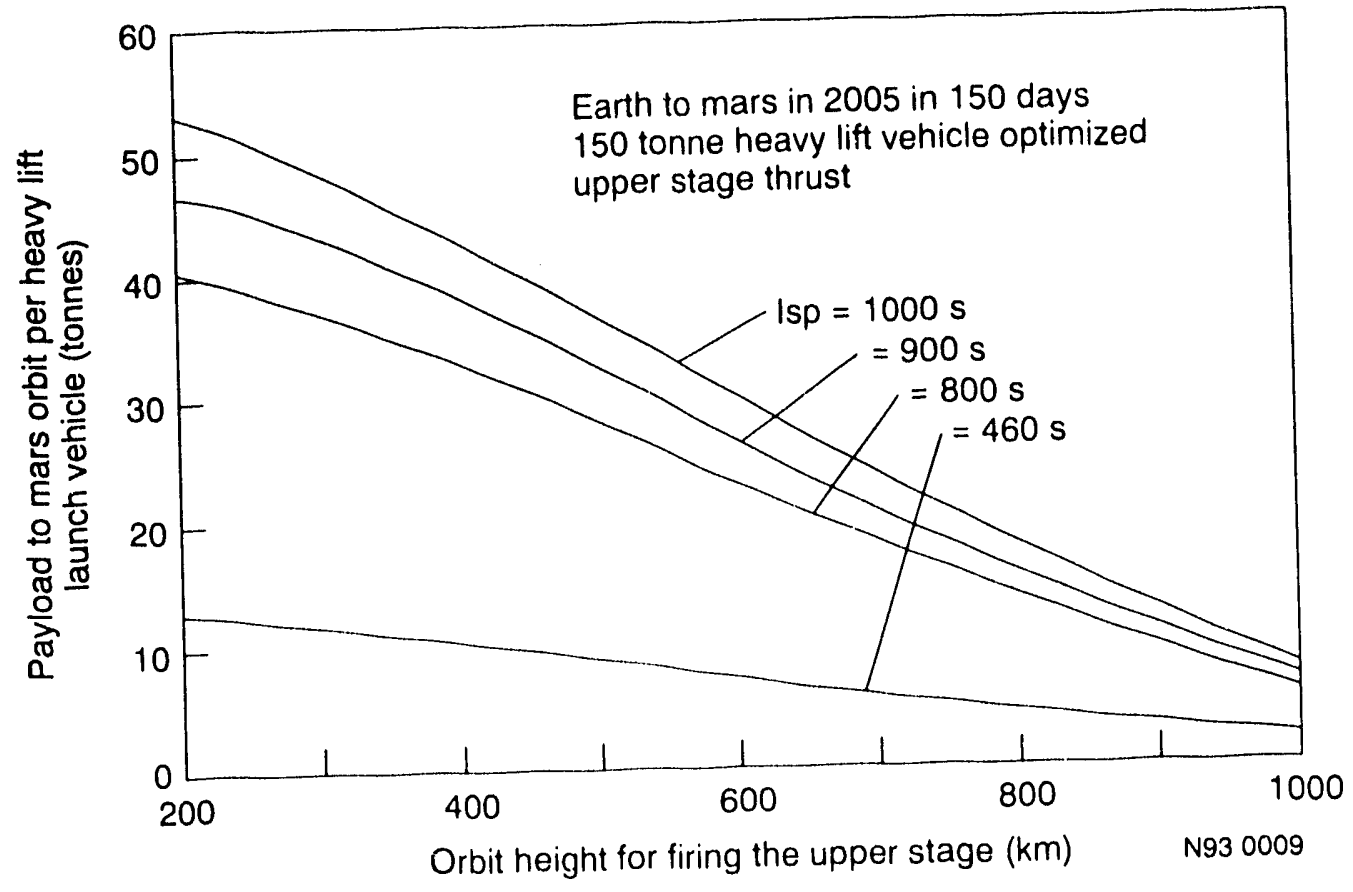

Figure 13. Mars payload performance vs. orbit height. 


\section{PROPOSED FUTURE ACTIVITIES}

A number of activities are proposed that would continue to meet the original objectives of the SIREN project. These are discussed below.

\subsection{Completion of the THOR Data Base}

THOR is an excellent program to evaluate the performance of not only SIREN missions, but all servicing and maintenance missions in space. A computerized compilation of all the information is missing today. Bits and pieces are located in many files. When the data base is completed, a rapid assessment can be made of different servicing, maintenance, and disposal missions. The program can also be used to assess methods of debris remediation. The needs for new technology programs can be identified.

The current THOR data base is very limited because the planned program was prematurely discontinued. The data base should be completed and a user's group established. The user's group would ensure the accuracy of the data base and suggest modifications to make the program more useful. The program would become a standard for space servicing industry and should become a joint NASA/DoD program.

\subsection{Support for International Safety Working Groups}

Technical support to the U.S./Russian Federation safety working group's proposed agenda item on prevention by external means the reentry of radioactive sources from space will be provided. Also, if other international working groups are formed, we will support these activities.

\subsection{Recommendations for Infrastructure and Design Modifications}

Recommendations for modifications to future nuclear-powered satellites, such as strong points at the center of mass, will be developed. Also, elements in the space infrastructure will be evaluated for ability to support SIREN-type missions and modifications recommended where applicable. By advanced planning, the use of robotic systems can be readily accommodated. However, where this has not been done, it is difficult to use robotic servicing, maintenance, and disposal systems. This is true for both nuclear and nonnuclear systems.

\subsection{Space Demonstration}

A relatively inexpensive SIREN mission demonstration project is proposed to show the feasibility of performing such a mission. It would take the form of an instrument package to view and measure radiation of an existing nuclear-powered satellite and the attachment of a simulated booster to the satellite. Such a project would demonstrate the key elements of a SIREN mission, including locating the satellite, launching an instrument package to the satellite, maneuvering and operating in the close proximity of the satellite, making high definition video pictures to assess the state of the satellite, and finally attaching an instrument package to the satellite.

In particular, the satellite might be the radioisotope-powered Transit Triad-01-1X. An airlaunched Pegasus vehicle is proposed to permit access to any inclination orbit because of its relative low cost (\$13 million per launch). It will use a standard bus, such as Quickstar (cost $\$ 13$ million), to avoid development costs. The Quickstar bus will provide the communications, power and maneuver rockets needed for the payload as well as the structure. About $100 \mathrm{~kg}$ of 
hydrazine is needed for space propulsion and maneuvering. The Pegasus vehicle will affect an orbital rendezvous and the Quickstar will provide about $75 \mathrm{~m} / \mathrm{s}$ for close-in maneuvers. For close-in measurements, video, radiation, and radar will be used. For capture, a robotic arm or net will be used. (These are the only nonstandard items proposed.) The mission will include approaching the satellite and making close-up measurements on the satellite's condition. There will be both radiation measurements of the radioisotopes onboard and high definition video pictures to examine surface features. Then, the SIREN craft will be maneuvered in line with the satellite and the speeds will be synchronized. Finally, the robotic arm will be locked onto the spacecraft or a net deployed around the spacecraft. Measurements will periodically be made to assess any change in status over time.

The total mission is projected to cost between $\$ 35$ and $\$ 40$ million. Parts could be performed as university projects. 


\section{SUMMARY}

The SIREN program is important because (a) it demonstrates an awareness of public concerns about space use of nuclear power and propulsion systems, and about the potential of nuclear materials reentering the biosphere, (b) it shows that precautionary actions are being taken to protect the biosphere, (c) it provides a mechanism for active public involvement in space nuclear safety, (d) it provides a means for international cooperation, (e) it is timely to establish international guidelines for space nuclear systems, and (f) it supports many emerging space activities, such as space debris remediation, servicing and maintenance in space, and such initiatives such as strategic defense and space exploration. 


\section{REFERENCES}

1. D. Buden, et al, "Systems to Prevent Nuclear Material from Reentering the Biosphere," AIAA/SAE/ASME/ASEE 28th Joint orpulsion Converence, Nashville, Tennessee, July 1992, AIAA-92-3271.

2. T. Albert, J. Lee, S. Lapin, J. Angelo, jr., Project SIREN: Technology for Space Nuclear Disposal and Debris Manatement, a report to the Strategic Defense Initiative Organization, October 1989.

3. D. Atkinson, et al, "Collision Damage to Nuclear Satellites," American Nuclear Society, Nuclear Technologies for Space Exploration, Jackson, Syoming, August 1992, pp.843-849.

4. D. J. Kessler, R. C. Reynolds, and P. D. Anz-Meador, Orbital Debris Envirronment for Spacecraft Designed to Operate in Low Earth Orbit, NASA TM 100471, 1989.

5. D. Atkinson, et al, "Mission Analysis and Trade Studies for Nuclear Reacotr Disposal Using THOR (Technology Hierarchy for Orbital Recovery, " American Nuclear Society, Nuclear Technologies for Space Exploration, Jackson, Wyoming, August 1992, pp. 850855.

6. B. W. Bartram and S. R. Tammara, "Aging Effects of U.S. Space Nuclear Systems Currently in Orbit," Ninth Symposium Space Nuclear Poer Systems Proceedings, Albuquerque, New Mexico, January 1992, pp. 929-936.

7. Organization for Economic Cooperation and Development Nuclear Energy Agency and Swedish National Institute of Radiation Protection in Stockholm, Emergency Preparedness for Nuclear-Powered Satellite, Stockholm, Sweden, 26-26, 1989. 

